\title{
FORCED VIBRATION TESTING AND ANALYSIS OF PRE- AND POST- RETROFIT BUILDINGS
}

\author{
A Thesis \\ Presented to \\ the Faculty of California Polytechnic State University \\ San Luis Obispo, California
}

\author{
In partial fulfillment \\ of the Requirements for the Degree
}

Master of Science in Architecture with a Specialization in Architectural Engineering

by

Erica Dawn Jacobsen

June 2011 
(C) 2011

Erica Dawn Jacobsen

ALL RIGHTS RESERVED 


\section{COMMITTEE MEMBERSHIP}

TITLE:

Forced Vibration Testing and Analysis of Pre- and PostRetrofit Buildings

AUTHOR: $\quad$ Erica Dawn Jacobsen

DATE SUBMITTED: June, 2011

COMMITTEE CHAIR: Graham Archer, Ph.D., P.Eng.

COMMITTEE MEMBER: Cole McDaniel, Ph.D., P.E.

COMMITTEE MEMBER: Kevin Dong, S.E.

COMMITTEE MEMBER: Deborah Wilhelm, M.A., M.P.S. 


\begin{abstract}
Forced Vibration Testing and Analysis of Pre- and Post- Retrofit Buildings

Erica Dawn Jacobsen
\end{abstract}

The primary goal of the thesis was to detect the retrofit through vibration testing of both buildings. The secondary goal focused on correctly identifying the behavior of the building through FVT, comparing that behavior to computational model predictions, and determining the necessary level of detail to include in the computational modeling. Forced vibration testing (FVT) of two stiff-wall/flexible-diaphragm buildings yielded natural frequencies and mode shapes for the two buildings. The buildings were nearly identical with the exception that one had been retrofitted. Both buildings were comprised of concrete shearwalls and steel moment frames in the north/south direction and moment frames in the east/west direction. The retrofit strengthened the moment connections and added braces to the perimeter walls in the east/west direction.

The natural frequencies were found through FVT by setting a 30-lb shaker on the roof of both buildings and sweeping through a range of frequencies in both the east/west and north/south directions. Accelerometers were placed on the building to detect the accelerations. The peaks on the Fast Fourier Transform (FFT) graphs indicated the frequencies at which the structure resonated. Mode shapes were tested for by placing the shaker in a position ideal for exciting the mode and setting the shaker to the natural frequency detected from the FFT graphs. The accelerometers were placed around the roof of the building to record the mode shape.

After testing, computational models were created to determine if the models could accurately predict the frequencies and mode shapes of the buildings as well as the effect of the retrofit. A series of increasingly complex computational models, ranging from hand calculations to 3D models, were created to determine the level of detail necessary to predict the building behavior. Natural frequencies were the primary criteria used to determine whether the model accurately predicted the building behavior. The middiaphragm deflection and base shear from spectral analysis were the final criteria used to compare these select models.

It was determined that in order to properly capture the modal behavior of the building, the sawtooth framing, major beams, and the lateral-force-resisting-system (LFRS) must be modeled. Though the mode shape of the building is dominated by the flexible diaphragm, the LFRS is necessary to model to accurately predict both the natural frequency of the building as well as the diaphragm deflection.

Keywords: Ambient Vibration Testing, Forced Vibration Testing, Retrofit, Flexible Diaphragm, Mode Shapes, Natural Frequencies 


\section{TABLE OF CONTENTS}

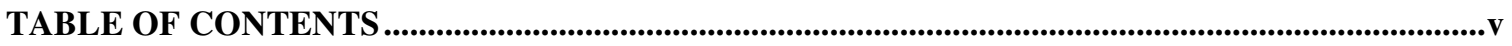

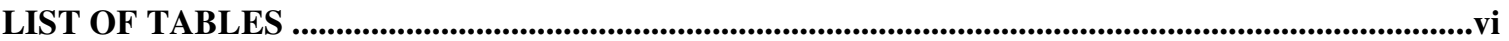

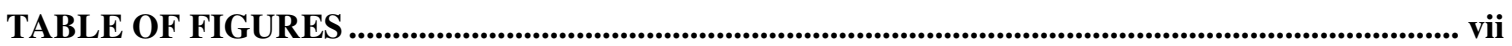

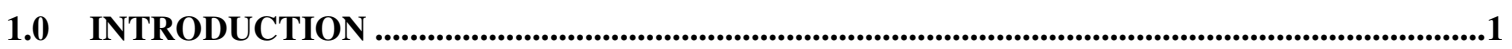

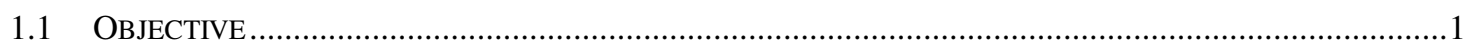

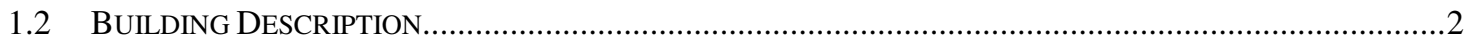

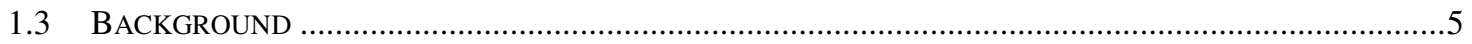

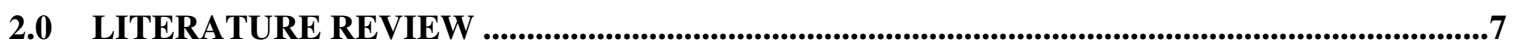

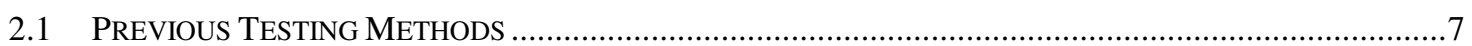

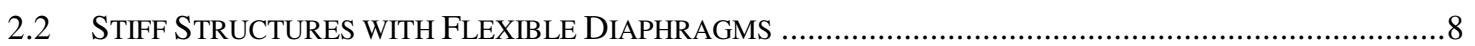

3.0 VIBRATION TESTING FOR MODAL CHARACTERISTICS ......................................................12

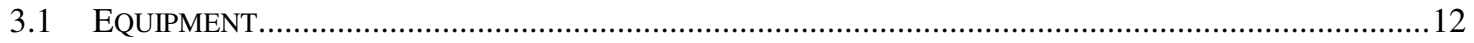

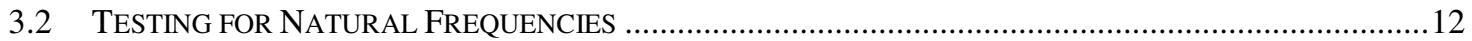

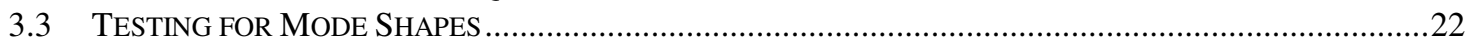

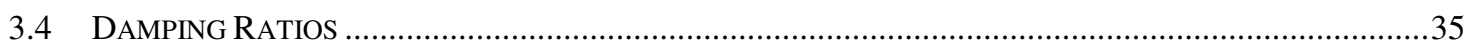

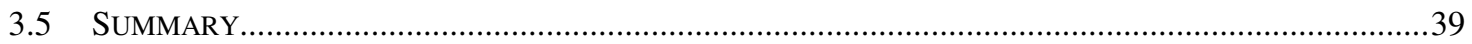

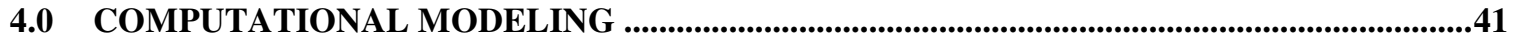

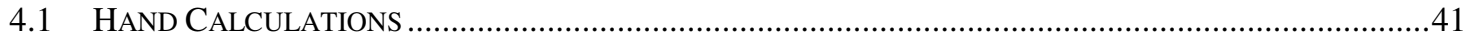

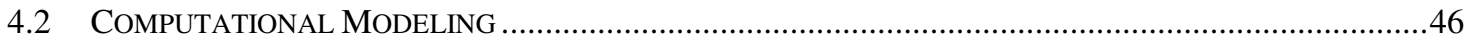

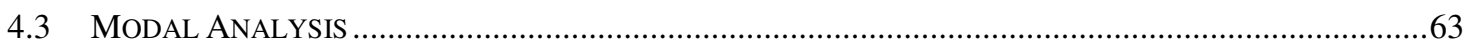

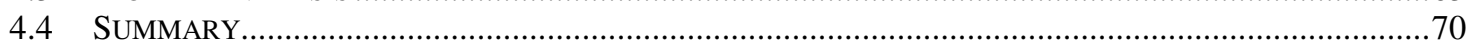

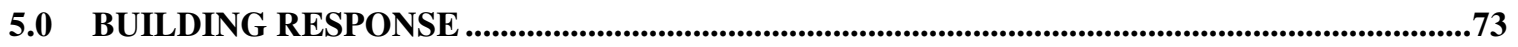

6.0 CONCLUSIONS .......................................................................................................................79

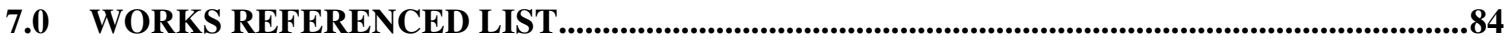

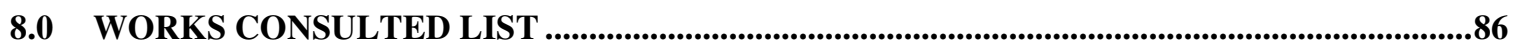




\section{LIST OF TABLES}

Table 1: Hand Calculation Results for NS Direction......................................................... 43

Table 2: Hand Calculation Results for EW Direction ................................................... 45

Table 3: Membrane Model Results for the NS Direction ............................................... 47

Table 4: Diaphragm Model With Sawtooth Results .......................................................... 51

Table 5: 3-D Model Results for NS Direction ........................................................... 54

Table 6: 3-D Model Results for EW Direction..................................................................... 61

Table 7: Comparison of Responses for Different Unretrofit Building Models ................ 75

Table 8: Comparison of Retrofit Building Responses .................................................. 76 


\section{TABLE OF FIGURES}

Figure A: Unretrofit Building Framing Plan and Section................................................ 3

Figure B: Retofit Building Framing Plan................................................................ 4

Figure C: Accelerometer Layout for NS Testing ............................................................ 13

Figure D: Natural Frequency Sweep in NS Direction of Unretrofit Building .................. 15

Figure E: Natural Frequency Sweep in EW Direction of Unretrofit Building ................ 16

Figure F. Accelerometer Layout for EW Testing ............................................................ 17

Figure G: Enlarged View of EW Sweep of Unretrofit Building …………………….... 18

Figure H: Natural Frequency Sweep in NS Direction of Retrofit Building .................... 19

Figure I: Natural Frequency Sweep in EW Direction of Retrofit Building...................... 20

Figure J: Enlarged View of EW Sweep of Retrofit Building ………………………..... 21

Figure K: Mode 1 Equipment Setup and Expected Mode Shape (Plan View) ................. 22

Figure L: Mode 2 Equipment Setup and Expected Mode Shape (Plan View) ................. 24

Figures M: Unswept Mode 1 of the Unretrofit Building ……………………………... 25

Figures N: Unswept Mode 2 of the Unretrofit Building ............................................... 25

Figure O: Pure Modes 1, 2, and 3 Used in Theoretical Example ..................................... 28

Figure P: Polluted Mode 2 Used in Theoretical Example .............................................. 28

Figure Q: Swept Mode 2 of Unretrofit Building …………………............................ 30

Figure R: Cross Section of Existing Roof.................................................................... 32

Figure S: Unswept Mode 1 of the Retrofit Building..................................................... 33

Figure T: Unswept Mode 2 of the Retrofit Building ..................................................... 33

Figure U. Swept Mode 2 for the Retrofit Building .......................................................... 34

Figure V: Damping Ratios for the Unretrofit Building ……............................................ 36 
Figure W: Damping Ratios for the Retrofit Building ............................................. 38

Figure X: Computer Model With Vertical Members Included..................................... 53

Figure Y: Section Showing Moment Frame Beams at Different Elevations ................... 56

Figure Z: Ambient Vibration of the Unretrofit Building in the EW Direction................. 66

Figure AA: Ambient Vibration of the Unretrofit Building in the NS Direction .............. 67

Figure BB: Ambient Vibration of the Retrofit Building in the EW Direction ................. 68

Figure CC: Ambient Vibration of the Retrofit Building in the NS Direction ................. 69

Figure DD: Response Spectra Used in Comparison of Models................................... 73 


\subsection{INTRODUCTION}

This thesis explores the behavior of two nearly identical concrete-shearwall buildings with flexible diaphragms, one of which has been seismically retrofitted. The purpose of this thesis is to use forced vibration testing (FVT) to detect the retrofit in the buildings and compare those test results to computational model predictions. The modal behavior of the two buildings is used as criterion for determining whether a computational model can accurately predict the building behavior and more specifically the retrofit. Mode shapes and natural frequencies are compared to all the computational models; select models are also analyzed by using spectral analysis. From this analysis the diaphragm deflection, base shear, and wall base shear are compared between the models; this comparison is used as an additional criteria for judging to what extent the models differ from one another. Through that comparison it is determined what detail is necessary in a model to accurately predict the behavior of the buildings.

\subsection{Objective}

The objective of this thesis is to use FVT to determine what effect the retrofit has on the building dynamics. The results from the testing are then compared to computational model predictions to conclude whether the computational model correctly predicts the effect the retrofit has on the building. Through the testing, modal information is gathered that is then compared to computational model predictions.

Currently, there is little research regarding the modal behavior of buildings with stiff shearwalls and flexible diaphragms. Another objective of this thesis is to analyze the 
ability of different computational models to effectively predict the natural periods as well as the mode shapes identified from the FVT. The level of detail necessary to effectively model the building is determined through the process of comparing computational results with FVT results. The criterion for determining the accuracy of the computational model is based on the natural frequencies and mode shapes.

\subsection{Building Description}

The experimentation for this thesis is performed on two of six nearly identical buildings, one of which was retrofitted in 2005 and one that was retrofitted after the testing in 2010. For the purpose of this thesis, the buildings will be referred to as the retrofit building $(\mathrm{RB})$ and the unretrofit building (URB). In order to capture the preretrofit and post-retrofit behavior of a building, it would typically be necessary to wait for construction of the retrofit to finish, therefore delaying the testing. By testing two nearly identical buildings, one with a retrofit and one without, waiting for construction was unnecessary, making these two buildings ideal for testing.

The buildings are located in Northern California and are both 120,000 square feet, 2-story commercial buildings with a waffle slab at the second floor and light frame wood and steel roof. At the bottom story there are three shearwalls around the perimeter and concrete columns on the interior. At the top story there are steel moment frames in the east/west direction and concrete shearwalls and intermediate moment frames in the north/south direction. Since the bottom story has concrete shearwalls on three sides and is partially underground due to the sloped site, the bottom story is over ten times stiffer 
than the top story, so according to the International Building Code (IBC 2006), the top story can be analyzed as a single-story building. The framing plan and cross section of the URB, as used in the analysis, is shown in Figure A, below.

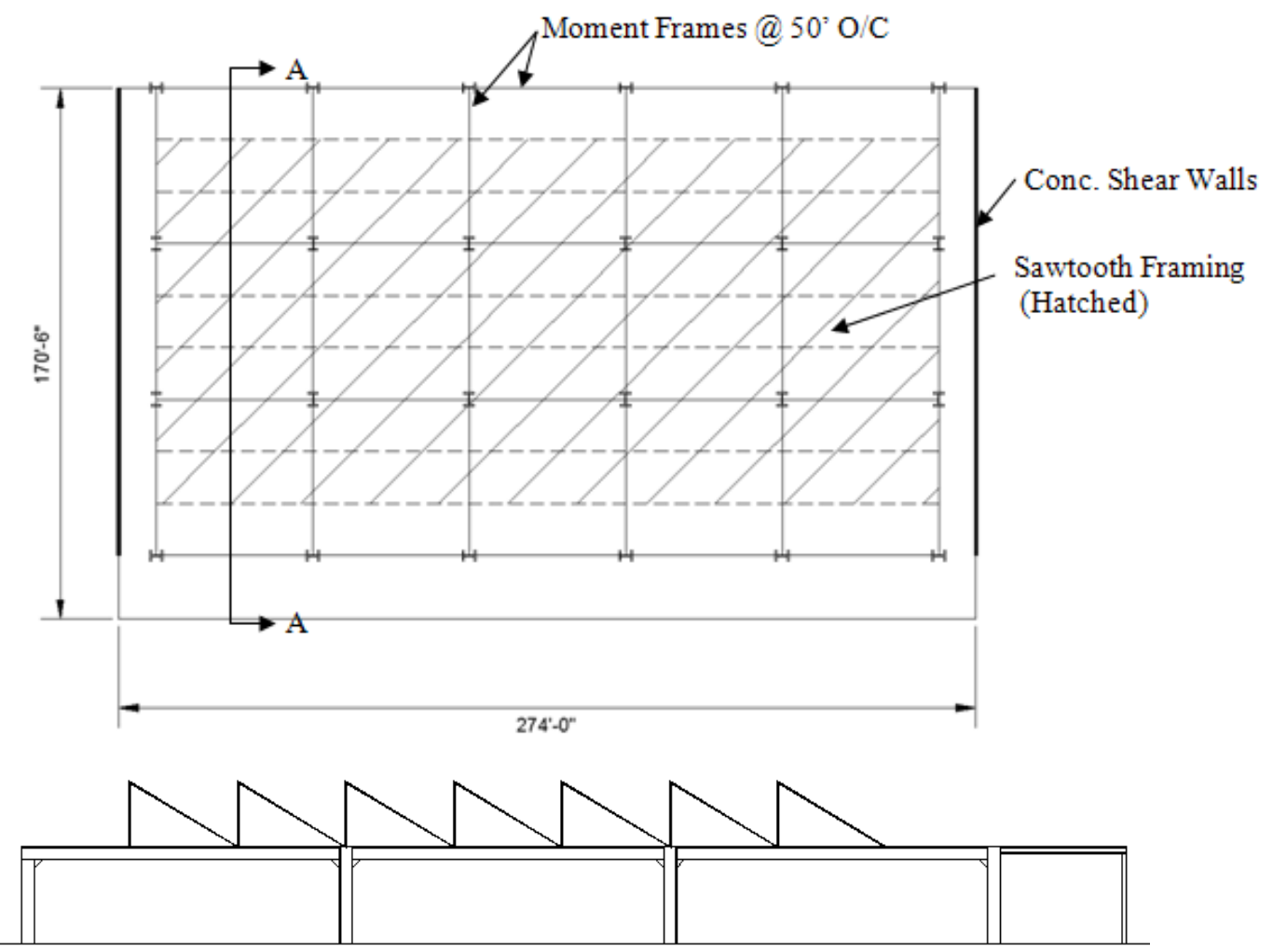

Figure A: Unretrofit Building Framing Plan and Section

Source: Jacobsen (2011)

The structure for both buildings has a hybrid roofing system consisting of steel girders and beams with wood joists and a plywood roof. A large percentage of the roof is also composed of sawtooth framing, as seen in Figure A. The plywood diaphragm is made more flexible by the sawtooth and because of the flexible diaphragm, each mode of both buildings only moves in one direction, east/west (EW) or north/south (NS), and is unaffected by modes in the other direction. 
The difference between the two buildings is the additional braces at the second story in the EW direction of the RB. The braces were added to stiffen the building and to reduce the load in the existing moment frames. The first story of the RB was determined to have adequate strength, so it was not retrofit. The framing plan for the RB is shown below in Figure B.

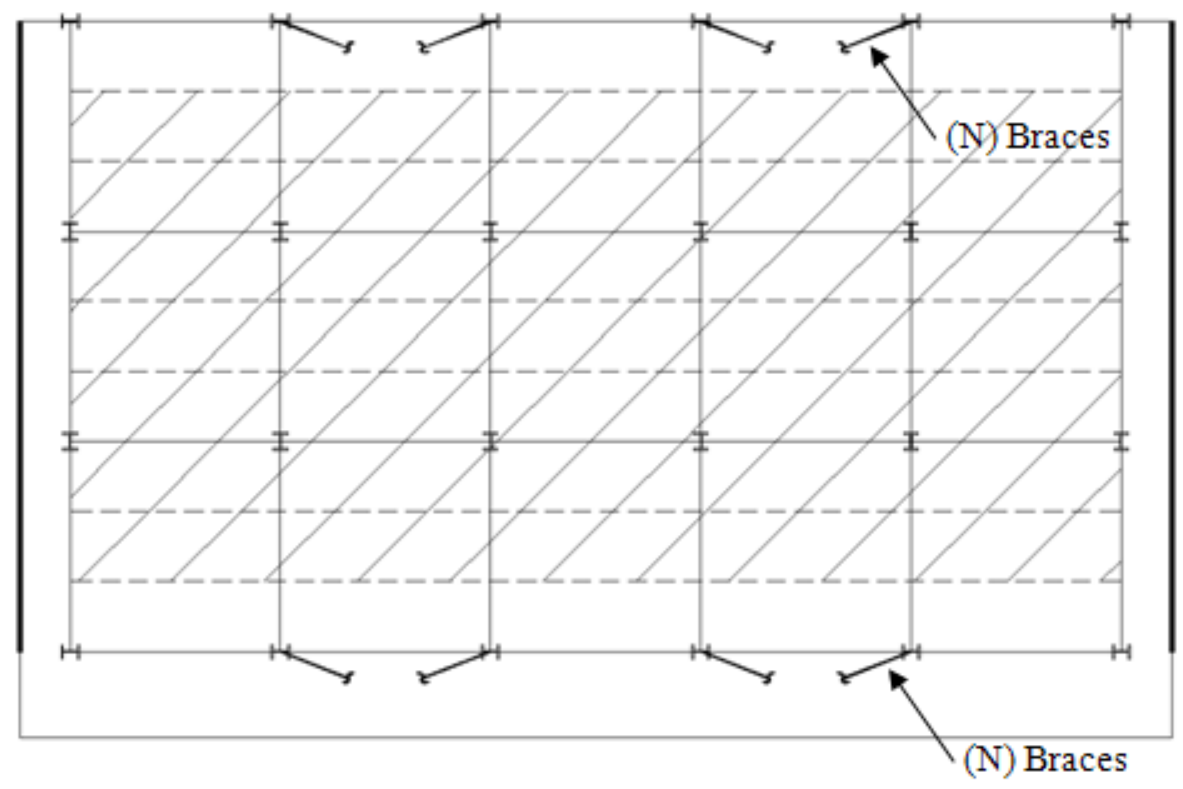

Figure B: Retofit Building Framing Plan

Source: Jacobsen (2011)

As illustrated in Figure B, the only significant change to the building is the addition of braces in the (EW) direction. This retrofit scheme would cause a potential change in the EW mode of the building, as well as, increase in the natural frequencies. Because the retrofit was primarily in the EW direction, the natural frequencies and mode shapes in the NS direction should not have been affected. This is proven in the testing and will be discussed in Section 3 . 


\subsection{Background}

The first step in most analyses is to determine the building's natural periods as well as the first several mode shapes and damping ratios. Computational models of existing buildings can be created that will output these mentioned responses.

Experimental testing of the building can be employed as well. Ambient vibration testing (AVT) and forced vibration testing (FVT) have been accepted methods for finding the fundamental periods of a building since the 1930s (Ivanovic 2000).

AVT requires placing accelerometers along the building and measuring the vibrations of the building caused by everyday occurrences such as mechanical equipment, wind, and traffic. In contrast, FVT involves shaking the building, typically the roof. The responses of the building to this force are then measured by accelerometers. The field effort involved in AVT is less than that for FVT because less equipment and set-up is involved (Trifunac 1972). However, the smaller the vibrations, the more difficult it is to detect the building's responses. Unless the frequency of those vibrations resonates with the building, it may be difficult to detect the natural frequency of the building with AVT. For this reason, FVT may be preferred regardless of the additional setup and equipment required.

Most FVT tests are preformed on tall, rigid diaphragm buildings. It should be noted that stiff buildings with flexible diaphragms are an often-overlooked category of seismic analysis, made apparent in the literature review. This oversight is also evident in computer programs. Many computer programs are designed for rigid diaphragms so their ability to predict the behavior of a flexible diaphragm is lacking. ETABS, a common 
engineering modeling program, restricts the option to rigid or semi-rigid diaphragm. In addition, the program does not include plywood or wood on the list of pre-programmed materials. Although these obstacles can be overcome in ETABs, caution should be exercised when trying to model flexible plywood diaphragms.

Some engineers believe that the natural frequencies of the building are determined by the stiffness of the lateral-force-resisting-system (LFRS), such as braced frames, moment frames, or shear walls. However, recent research, discussed in the literature reviews, reveals that in a building with significantly stiffer walls than diaphragm, the first several natural frequencies are governed by the flexible diaphragm. Consequently, the mode shapes of the building resemble those of a flexible beam rather than the conventional rigid-body translational mode shapes. FEMA 310 (FEMA 1998) has provisions regarding the retrofit of such buildings, but these provisions depend upon the natural frequency of the building. It is only in recent testing that researchers are beginning to understand the flexible diaphragm behavior in stiff buildings, and more testing is required before an accurate prediction of the natural frequencies is codified, which is also discussed in the literature review. 


\subsection{LITERATURE REVIEW}

The buildings' behavior is best represented by the behavior of a stiff building with a flexible diaphragm similar to masonry buildings with plywood roofs. Research regarding the behavior of these buildings, as well as the testing methods, is explained below.

\subsection{Previous Testing Methods}

Ambient and forced vibration testing has been explored both separately and in comparison to each other. Ivanovic (2000) performed an ambient vibration test on a building in Van Nuys, California and Luco, Trifunac, and Wong (1988) performed a forced vibration test on the Milikan Library in Pasadena, California. The definition used in this thesis for forced and ambient vibration arose from these sources. Trifunac (1972) tested two buildings, a 22-story steel frame building and a nine-story concrete frame building, and determined that forced and ambient vibration yielded similar results. However, both buildings discussed by Trifunac were considerably taller than the buildings investigated in this thesis and, therefore, more susceptible to ambient vibrations. Because there were fewer case studies about vibration testing of shorter buildings, and fewer still regarding buildings with flexible diaphragms, both FVT and AVT were performed despite Trifunac's findings. However, Trifunac's conclusion that forced and ambient vibration yield similar results eventually proved to be true for the testing done in this thesis as well. 
McDaniel and Archer (2009) detail the AVT and FVT set-up as well as the equipment used in this thesis. In their conference paper, McDaniel and Archer used FVT to identify the first three natural frequencies and mode shapes of a two-story concrete building. In their paper they proved that a 30-lb shaker could excite the natural frequencies of a full-size building, results that were later corroborated with computer models. Their research provided the basis for the experiment done in this thesis.

\subsection{Stiff Structures with Flexible Diaphragms}

There is a movement in the engineering community to correct the code provisions for stiff structures with flexible diaphragms. The SEAOC Seismology Committee (2008) propose that an entirely new approach in determining the natural frequency of stiff structures with flexible diaphragms is needed. The current lumped-mass model only takes into account the rigidity of the LFRS and not the diaphragm. Though research has investigated new methods for determining these buildings' natural frequencies, more research is required before code changes can occur.

Freeman, Searer, and Gilmartin (2002) proposed that code provisions do not accurately describe the behavior of these structures when excited by earthquake ground motions. Their article suggests a method for finding the earthquake loads in a building based on the first two modes of motion; the first fundamental mode is the in-plane bending of the diaphragm as though it were a horizontally supported beam and the second fundamental mode of vibration is due to the out-of-plane bending of the pre-cast concrete tilt-up walls. While the first mode was found in the testing for this thesis, the second 
mode was not present because there were no shearwalls along the longitudinal edges of the buildings.

Studies suggest that a flexible diaphragm behaves similar to that of a simply supported beam. Rao (2004) presents equations for finding the natural frequencies of a simply supported beam by looking at the rotary inertia of the beam alone, the shear stiffness alone, and then with neither parameters. The analysis based on the equations by Rao (2004) was used as a preliminary method to compute the natural frequencies of the buildings, but ultimately the model was too simplistic to capture the modal behavior of the buildings.

There was some debate on whether the flexible diaphragm remained linear through high excitation. The accelerations exerted on the buildings in this thesis are low amplitude, not enough to overcome the internal frictions of connections, so the fundamental periods should be lower than those found if the buildings were excited at earthquake-level forces. Paquette and Bruneau (2005) performed a full scale, shake table test on a one-story masonry building with a flexible diaphragm, and discovered that the diaphragm in their experiment remained linear elastic through their pseudo-dynamic testing. This conclusion suggests that the natural frequency of the diaphragm will not shift at higher force levels.

In direct contrast to Paquette and Bruneau (2005), Rogers and Tremblay (2005) believed the behavior of a flexible diaphragm was non-linear due to connection failure at the panels. Camelo (2003) performed vibration testing on five wood buildings and also 
found that the natural frequency shifted as much as $40 \%$ as the amplitude of the accelerations increased. The American Plywood Association (APA) deflection equation (SEAONC 2001) for flexible diaphragms includes four components: bending deformation, shear deformation, nail slip, and chord slip. Nail slip in particular does not have a linear force-displacement relation and so the APA equation suggests that the stiffness of the diaphragm is load dependant. In Freeman, Searer, and Gilmartin (2002), they separated the period of the diaphragm into three categories: “(a) initial period at low amplitude motion, (b) design level at moderate amplitudes below yield level and (c) inelastic response at reasonably acceptable ductility limits."

Based on this research, it seems probable that the period of the diaphragm shifts when the accelerations have higher amplitudes, but due to the limitations of the testing equipment, 30-lbs as the maximum force of the shaker, testing the two buildings at higher amplitudes was not possible. There was also concern that a higher amplitude shaker might have proven destructive to the building. While Freeman, Searer, and Gilmartin (2002) don't explain what levels of force they considered to be low amplitude, they do state that level (b) was considered appropriate for design forces and level (c) should be considered for maximum displacements. The $30-1 b$ shaker used in the testing for this thesis is well below design forces, and so the building frequencies found during testing are at the lowest level, level (a). As a result of Camelo's (2003) research it was speculated that the frequencies found in the testing for this thesis are approximately $70 \%$ 
of what they will be during an earthquake, but more research will have to be conducted to state definitively. 


\subsection{VIBRATION TESTING FOR MODAL CHARACTERISTICS}

Ambient and forced vibration tests were performed on both buildings to identify the natural frequencies as well and the mode shapes of each building. The initial tests swept for the natural frequencies and subsequent tests yielded the mode shapes.

\subsection{Equipment}

The FVT was performed with a linear shaker capable of delivering a 30-lb force. A signal generator was used to set the shaker to vibrate at any frequency within $2 \mathrm{~Hz}$ to 20Hz. The signal generator also had the option to sweep through a range of frequencies in a two minute cycle. This function was used to locate the natural frequencies of the building. The vibrations that the building exhibited were detected through the use of piezoelectric 5-g accelerometers that were sensitive to a micro-g. Three accelerometers were used to capture the NS translational, the EW translational, and the rotational component of the accelerations.

\subsection{Testing for Natural Frequencies}

The accelerometers were first placed on the roof of the RB near the center of the diaphragm facing the north direction. Accelerometers A and $\mathrm{C}$ were located in the middle of the south edge of the diaphragm with A facing in the north direction and $\mathrm{C}$ in the east. Accelerometer B was set facing the north direction 16' east of accelerometers A and $\mathrm{C}$ as shown in Figure $\mathrm{C}$, on the following page. 


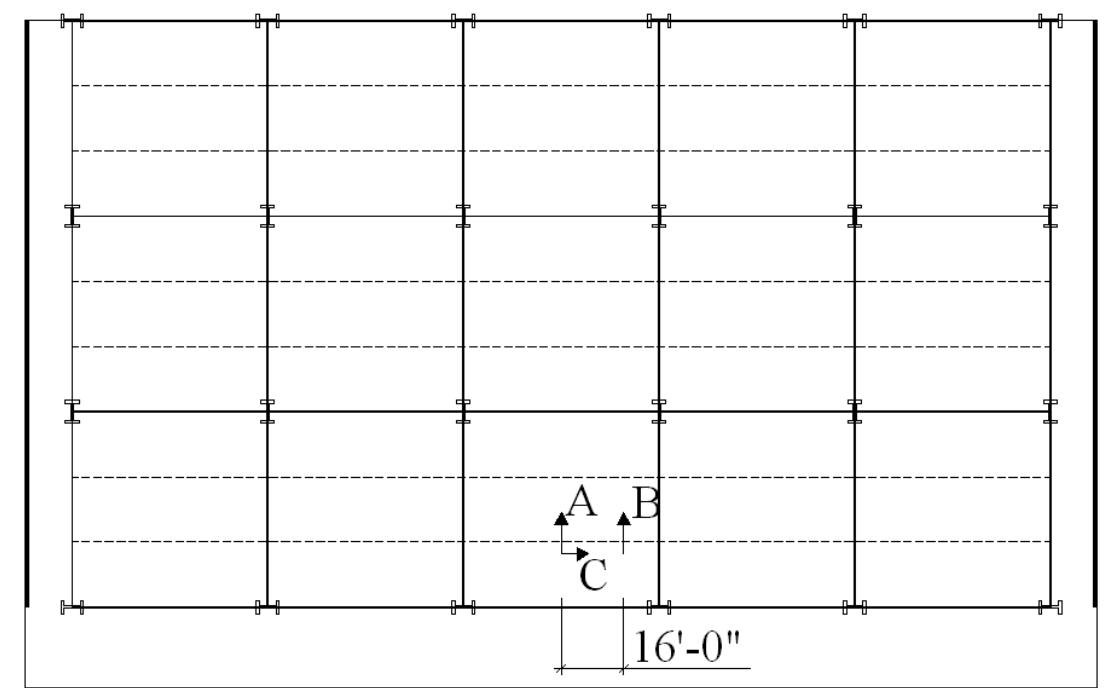

Figure C: Accelerometer Layout for NS Testing

Source: Jacobsen (2011)

The difference between the A and B accelerometers was converted into a rotational component by using the equation

$$
\operatorname{Rot}=\frac{(\mathrm{A}-\mathrm{B}) \times 16^{\prime} \times 12^{\prime \prime} / \prime^{\prime}}{\mathrm{g}} .
$$

Eq. 1

where Rot is the rotational component (unitless),

$\mathrm{A}$ is the acceleration in accelerometer $\mathrm{A}(\mu \mathrm{gs})$,

$\mathrm{B}$ is the acceleration in accelerometer $\mathrm{B}(\mu \mathrm{gs})$,

and $\mathrm{g}$ is the acceleration due to gravity (in- $\mathrm{s}^{2} / \mathrm{ft}$ ).

Though B was not required to be located sixteen feet from A, by placing the accelerometers at that distance, the rotation of the building was approximately the same amplitude as the translational accelerations, allowing all three components to be displayed on the same plot.

Forced Vibration Testing of Pre- and Post- Retrofit Buildings 
An ambient vibration test was performed over a range of frequencies from $2 \mathrm{~Hz}$ to $8 \mathrm{~Hz}$, shown in Figures $\mathrm{D}$ and $\mathrm{E}$ on the following pages. Ten two-minute recordings were taken and then averaged to produce the ambient vibration graphs.

After the ambient vibration test was complete, the shaker was placed at the middle of the south edge of the diaphragm facing NS direction to excite the first mode. The first mode shape of the building is the diaphragm flexing between the rigid shear walls like a beam. As stated previously, the NS and EW modes are uncoupled due to the flexibility of the diaphragm. A flexible diaphragm has little rotational component in the first several modes and mode shapes of a flexible diaphragm have motion in one direction only. This modal behavior is because the diaphragm does not couple the NS and EW motions into a single mode. If a diaphragm were completely flexible, then all mode shapes would only have motion in a single direction. Therefore the EW and NS modes are unaffected by each other.

The graph in Figure D on the following page shows the responses acquired at different testing positions. The shaker faced the NS direction to isolate the NS mode, faced the EW direction to isolate the EW mode, and then was turned $45^{\circ}$ from the orthogonal axes of the building, so all modes had the potential to be excited. 


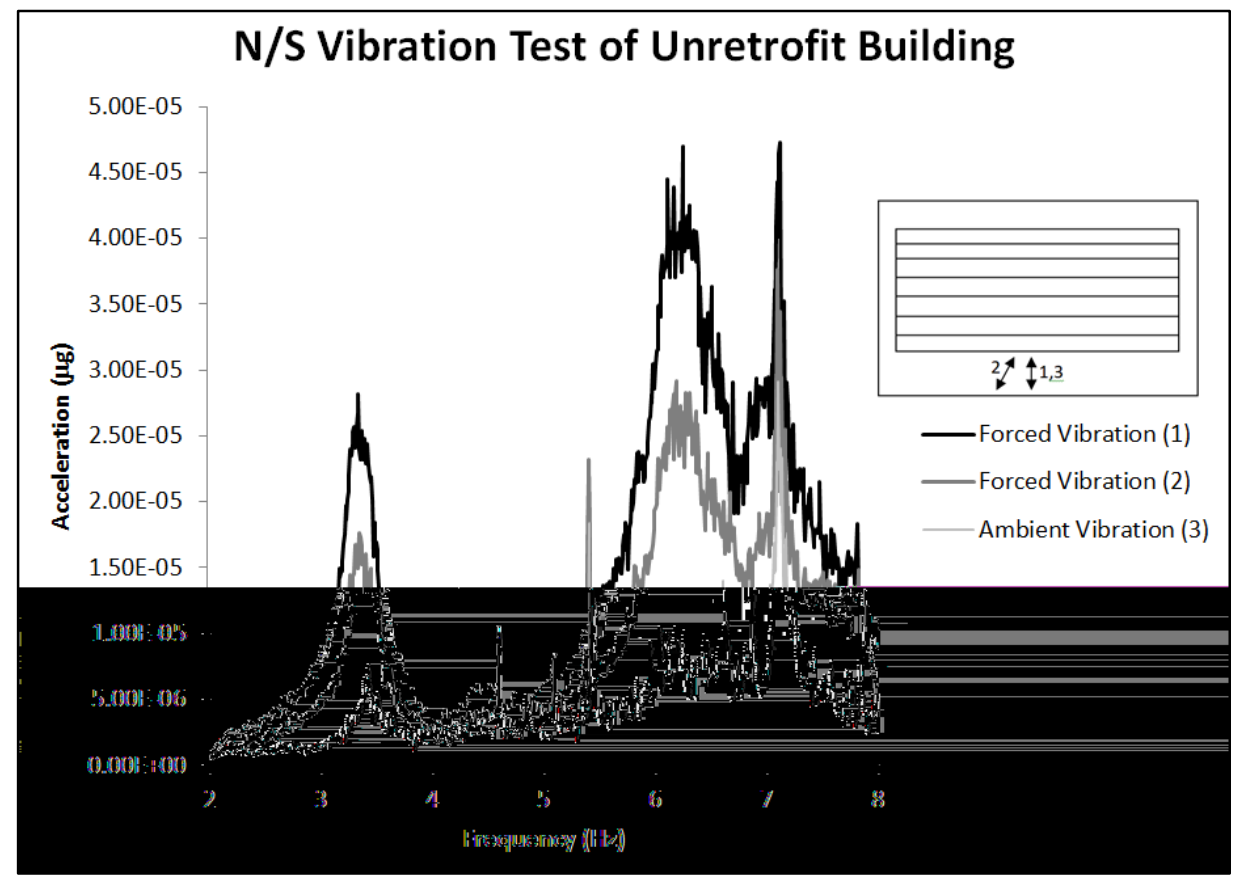

Figure D: Natural Frequency Sweep in NS Direction of Unretrofit Building Source: Jacobsen (2011)

Figure D shows the frequency range that was swept, and the peaks on the graph indicate where the natural frequencies lie. As illustrated in Figure D, the natural frequencies for the URB were $3.35 \mathrm{~Hz}$ and $6.18 \mathrm{~Hz}$, for Mode 1 and Mode 2 respectively. The peaks for AVT and FVT did line up, although the magnitude of the peaks is greater with the FVT. Similarly, the FVT performed at an angle, position 2, has a smaller amplitude than the FVT oriented directly NS.

The sweep in the EW direction, from $2 \mathrm{~Hz}$ to $10 \mathrm{~Hz}$, for the URB is shown in Figure E on the following page, and as in Figure D, the position of the shaker is shown in the upper right corner of the figure. 


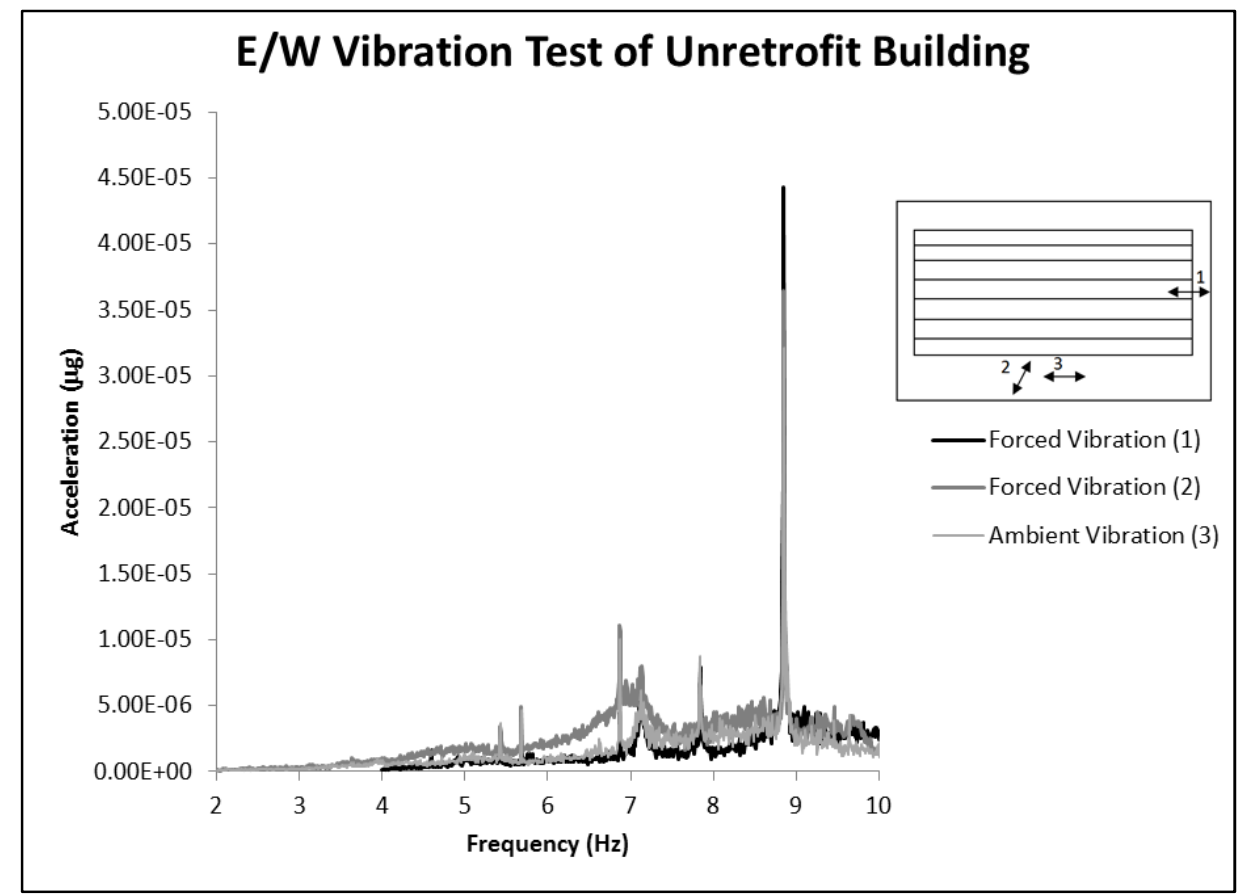

Figure E: Natural Frequency Sweep in EW Direction of Unretrofit Building Source: Jacobsen (2011)

While the accelerometers for the NS direction were always located at the center of the south side of the diaphragm, the EW direction had little response at the south edge of the diaphragm, positions 2 and 3, so the accelerometers and shaker were relocated to the east side of the building at position 1, shown on the following page in Figure F. 


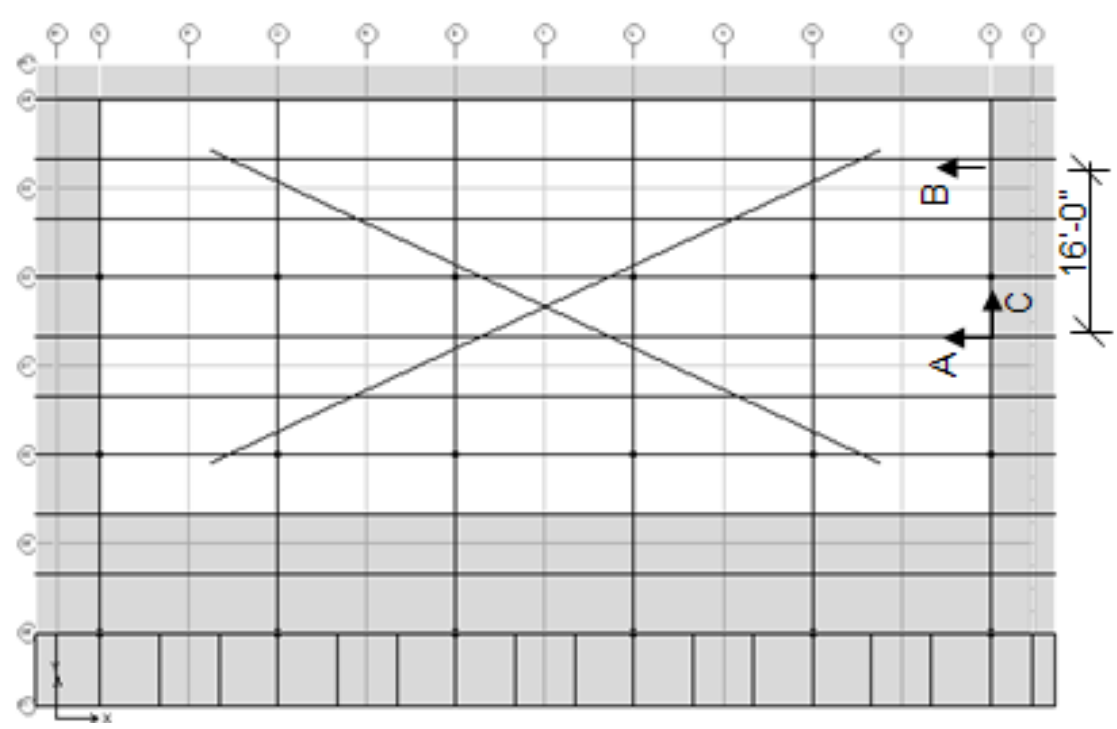

Figure F. Accelerometer Layout for EW Testing

Source: Jacobsen (2011)

The expected mode shape of a flexible diaphragm, according to Freeman, Searer, and Gilmartin (2002), is that of a simply supported beam, so by placing the shaker in the middle of the east edge, the natural frequency should have been more easily excited than when the shaker was placed on the edge of the diaphragm.

Though there is a large peak shown at $9 \mathrm{~Hz}$ in Figure E, a peak that sharp indicates the oscillation of mechanical equipment, such as an HVAC unit, rather than a building response. The width of the peak indicates the damping (Chopra 2007), therefore a sharp peak indicates low damping which is inherent in mechanical equipment. On both buildings there were HVAC units that did not appear to be isolated from the roof. The sharp peak shown in Figure $\mathrm{E}$ is the natural frequency of the fan in one of the HVAC units, not the building. Figure $\mathrm{G}$ on the following page shows an enlarged view of the EW sweep. 


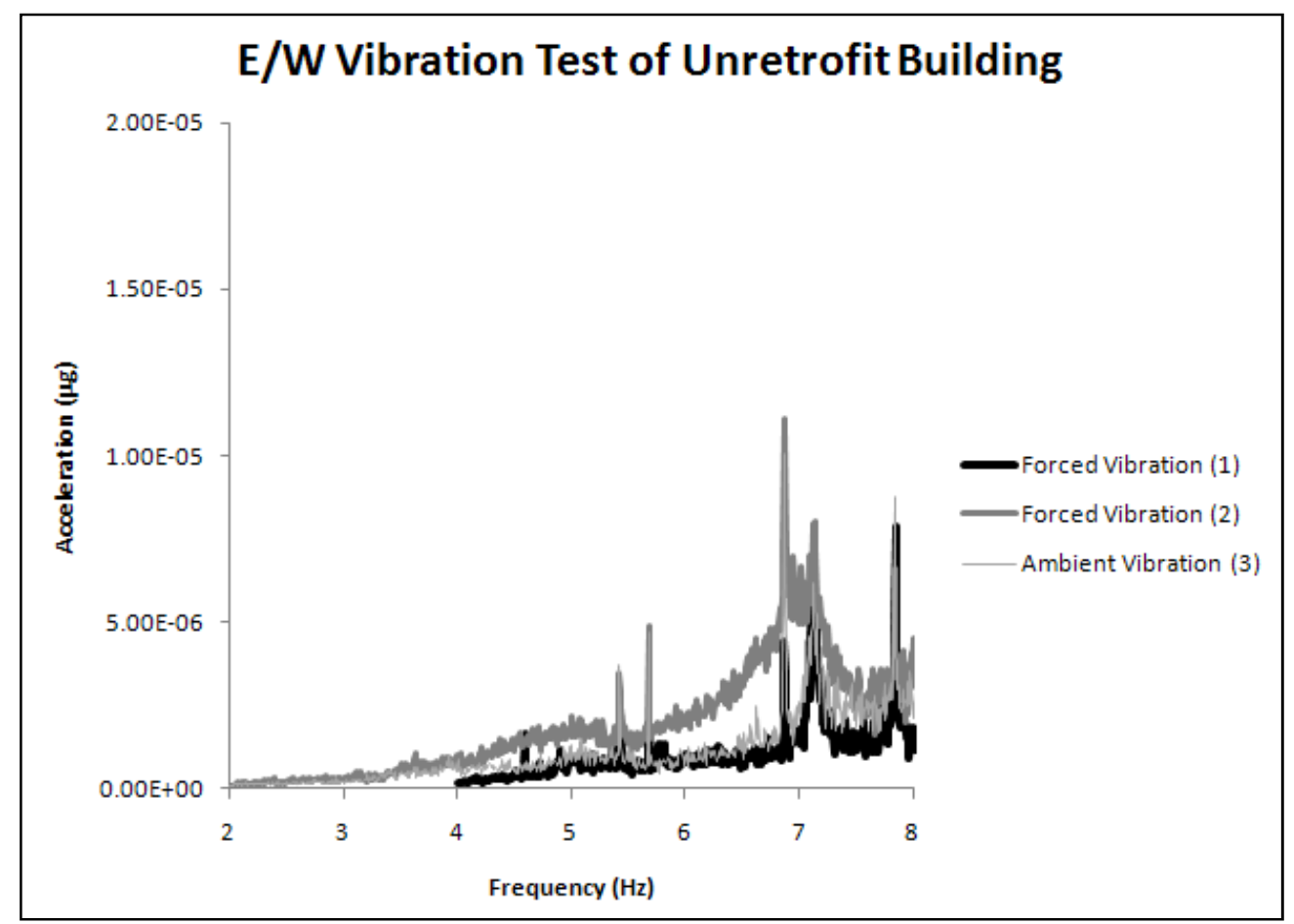

Figure G: Enlarged View of EW Sweep of Unretrofit Building Source: Jacobsen (2011)

As seen in Figure G, the only peak appears to be at 7.1 Hz; however, the low accelerations suggest that the peak is not an EW mode. Referring again to Figure D, there was a peak in the NS direction at $7.1 \mathrm{~Hz}$ with a stronger response than the EW direction; $50 \mu \mathrm{gs}$ were recorded in the NS direction as opposed to $5 \mu \mathrm{gs}$ in the EW. This data suggests that the peak at $7.1 \mathrm{~Hz}$ was more likely a shadow of one of the NS modes, rather than its own mode. Although testing was done in the EW direction multiple times and in multiple positions, no natural frequencies between $2 \mathrm{~Hz}$ and $8 \mathrm{~Hz}$ were detected. An AVT and a FVT were run in both directions for the RB as well. The AVT detected accelerations in the range of $2 \mathrm{~Hz}$ to $8 \mathrm{~Hz}$ at the midpoint of the diaphragm as seen in Figure $\mathrm{H}$ on the following page. After the ambient test, a forced vibration test 
was run in the NS direction from $2 \mathrm{~Hz}$ to $8 \mathrm{~Hz}$, and an angled sweep was performed from $2 \mathrm{~Hz}$ to $8 \mathrm{~Hz}$. The position of the shaker is displayed on the diagram at the upper right corner of the figure.

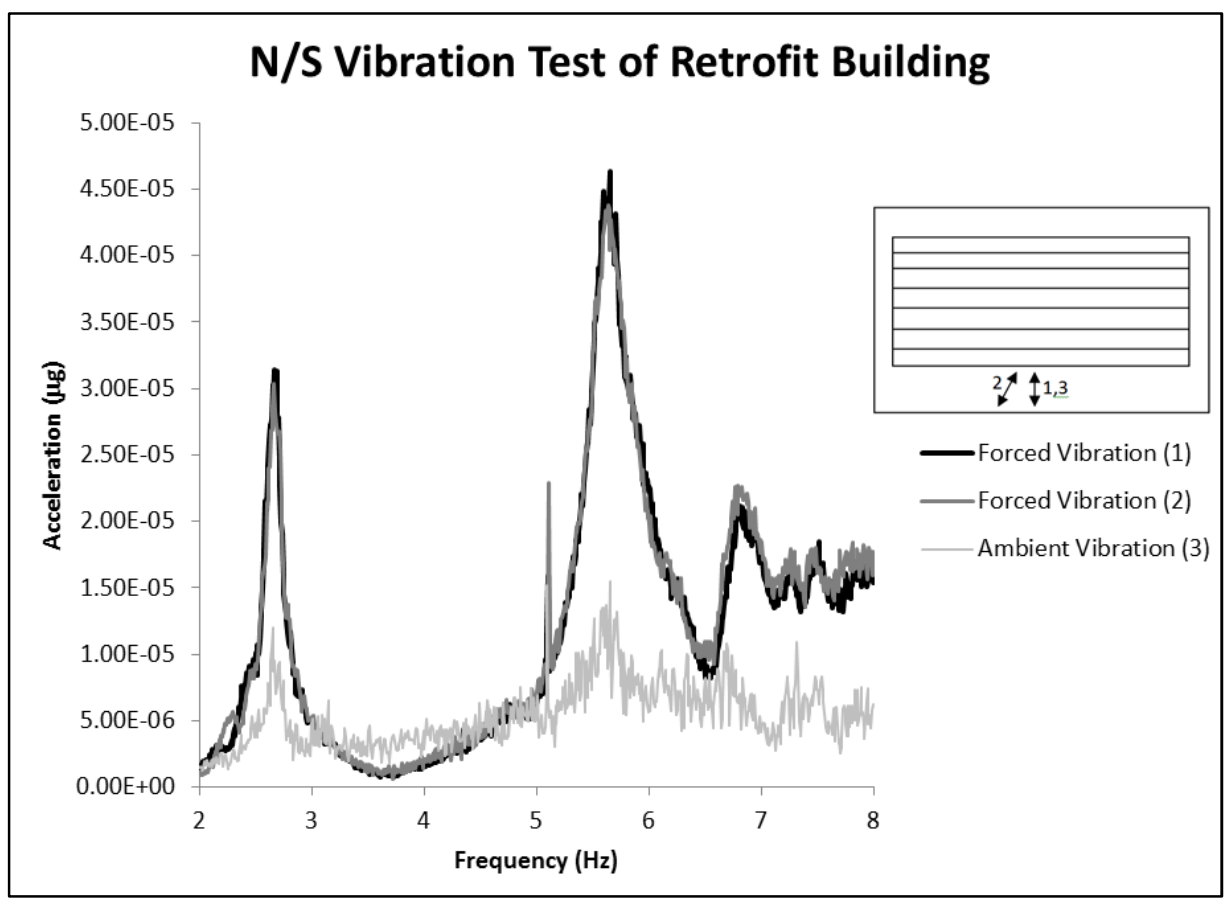

Figure H: Natural Frequency Sweep in NS Direction of Retrofit Building Source: Jacobsen (2011)

The natural frequencies in the NS direction are clearly delineated in Figure $\mathrm{H}$ at $2.63 \mathrm{~Hz}$ and $5.58 \mathrm{~Hz}$. Using the same method used with the URB, the accelerometers were placed at the middle of the diaphragm.

The shaker cycles through all the frequencies in the range during the two minute recording and only hits the natural frequency of the building for a moment before moving onto the next frequency. The accelerometers are able to pick up that momentary resonance before the shaker changes frequency, but there was concern that the natural frequency might not be detected if the shaker was at that frequency for too brief time. 
Considering this concern, for the EW mode, the shaker and accelerometers were placed on the east edge and the shaker swept from $2 \mathrm{~Hz}$ to $18 \mathrm{~Hz}$ in two different sweeps. The first sweep was from $2 \mathrm{~Hz}$ to $9 \mathrm{~Hz}$, and the second sweep was from $8 \mathrm{~Hz}$ to $16 \mathrm{~Hz}$.

Similar to the unretrofit building, the EW sweep on the retrofit building did not detect any natural frequencies between $2 \mathrm{~Hz}$ and $10 \mathrm{~Hz}$. Figure I below shows the sweeps and the areas where no clear peaks are apparent.

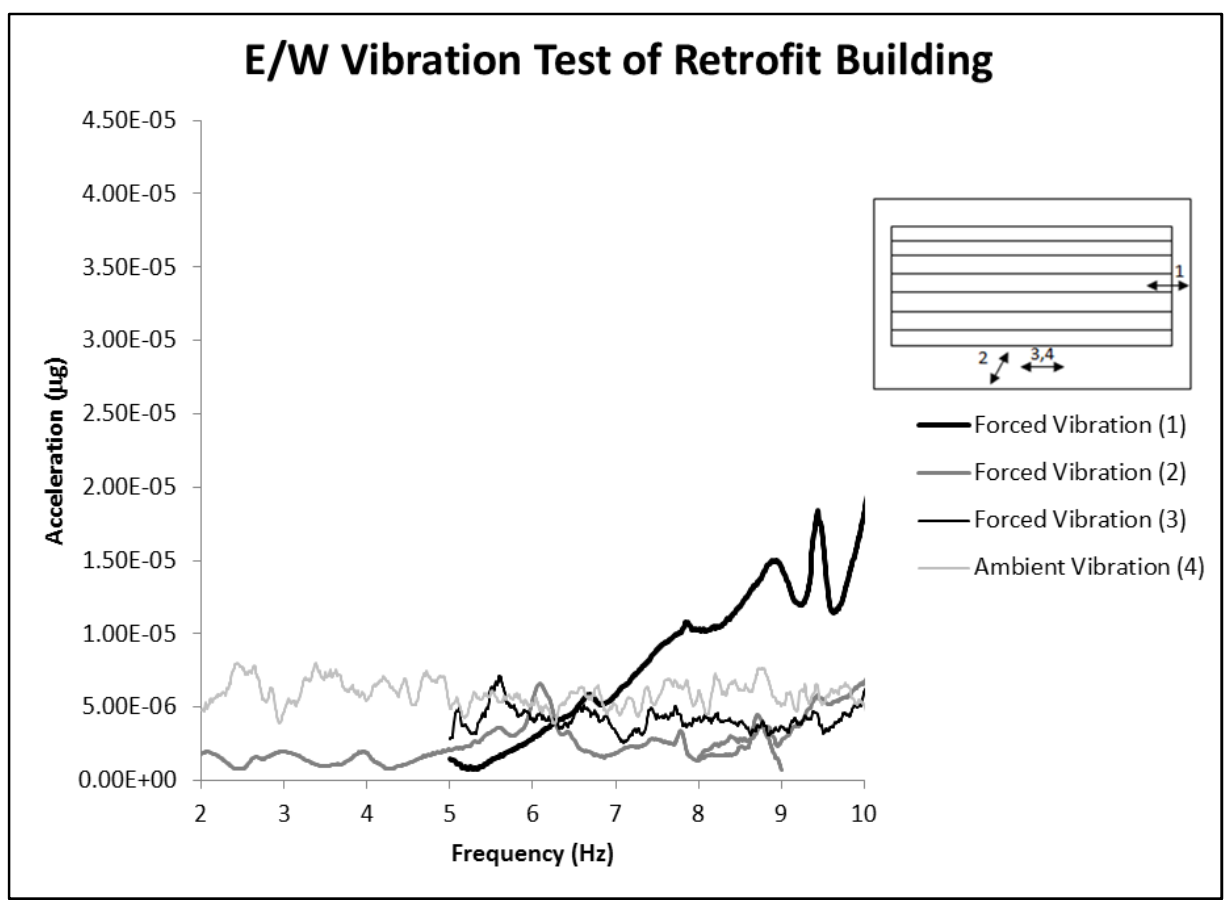

Figure I: Natural Frequency Sweep in EW Direction of Retrofit Building Source: Jacobsen (2011)

The shaker and accelerometers were placed at different points on the buildings, and the only apparent peak was in position 1 at $11 \mathrm{~Hz}$, however the peak is beyond the range of interest from a structural dynamics perspective. In addition, computational models suggest that the fundamental frequency of the retrofit building should have been 
anywhere from $2.5 \mathrm{~Hz}$ to $4 \mathrm{~Hz}$ but a closer view of the EW sweep, shown in Figure $\mathrm{J}$ below, reveals no peaks.

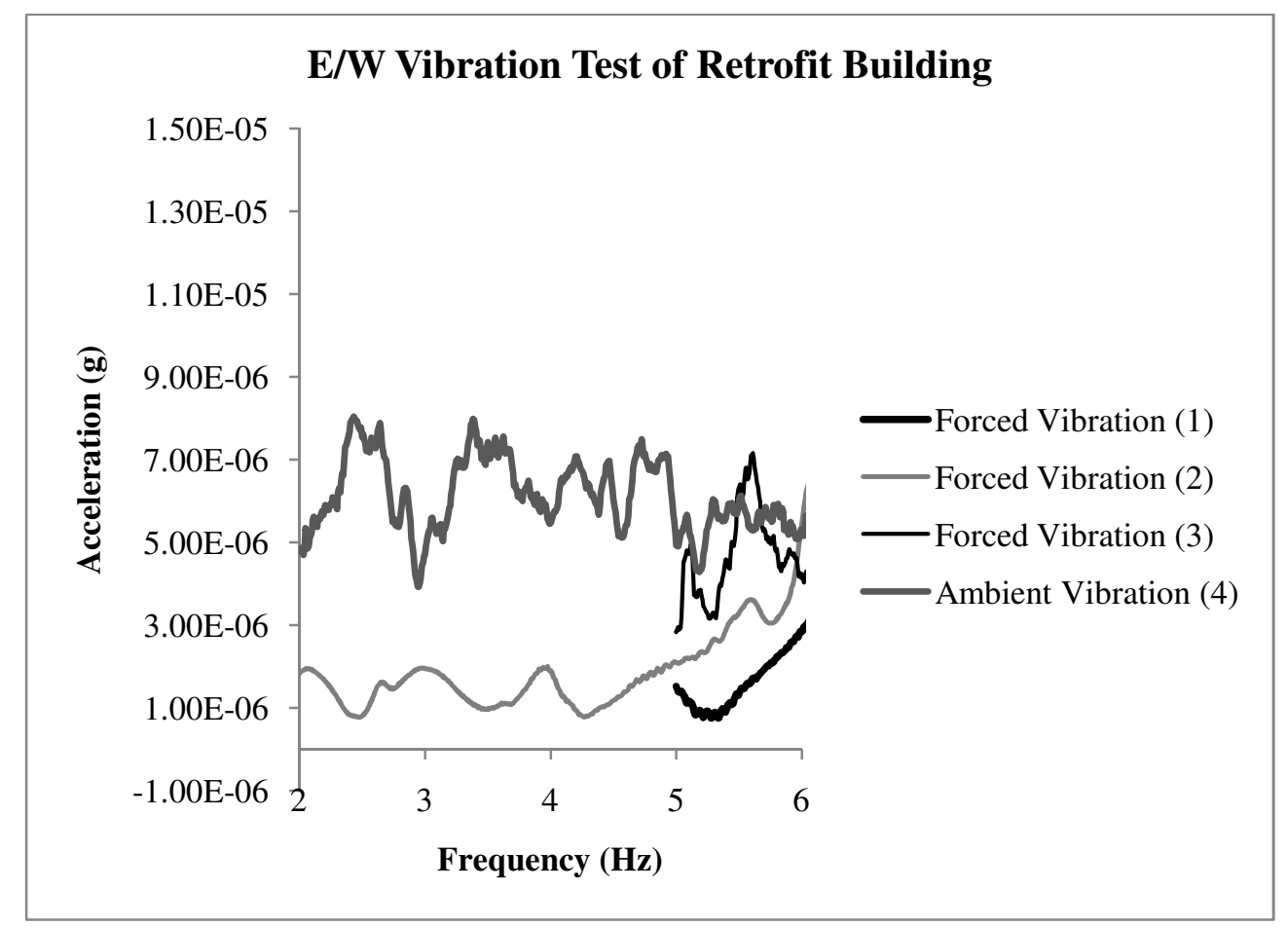

Figure J: Enlarged View of EW Sweep of Retrofit Building Source: Jacobsen (2011)

As illustrated in Figure $\mathrm{J}$ there are no peaks to indicate that the fundamental frequency in the EW direction was in the range of $2 \mathrm{~Hz}$ to $6 \mathrm{~Hz}$. In the NS readings the various forced vibration tests as well as the ambient test lined up, although with differing amplitudes. The readings for the EW direction did not line up, but since all the readings were below $10 \mu \mathrm{gs}$ the ambient vibrations could have distorted the readings differently each time. The peak of the natural frequency should have been clear above the ambient noise; that there is no peak in Figure $\mathrm{J}$ suggests there was no natural frequency in the tested range. 


\subsection{Testing for Mode Shapes}

After the natural frequencies for both buildings were determined, another round of testing began to map the mode shapes, the natural shape of the building when vibrating at a resonant frequency. The mode shapes were mapped for the first two natural frequencies of each building in the NS direction. As seen in Figure G on page 18 and Figure I on page 21, the natural frequencies in the EW direction were undetectable and so the focus of the testing became centered on the NS direction of the buildings. In order to map the mode shapes of both buildings, the shaker was placed at a point along the diaphragm that would maximize one mode shape while minimizing the other mode shapes. Figure K below shows the shaker positioned for Mode 1 and the expected mode shape.

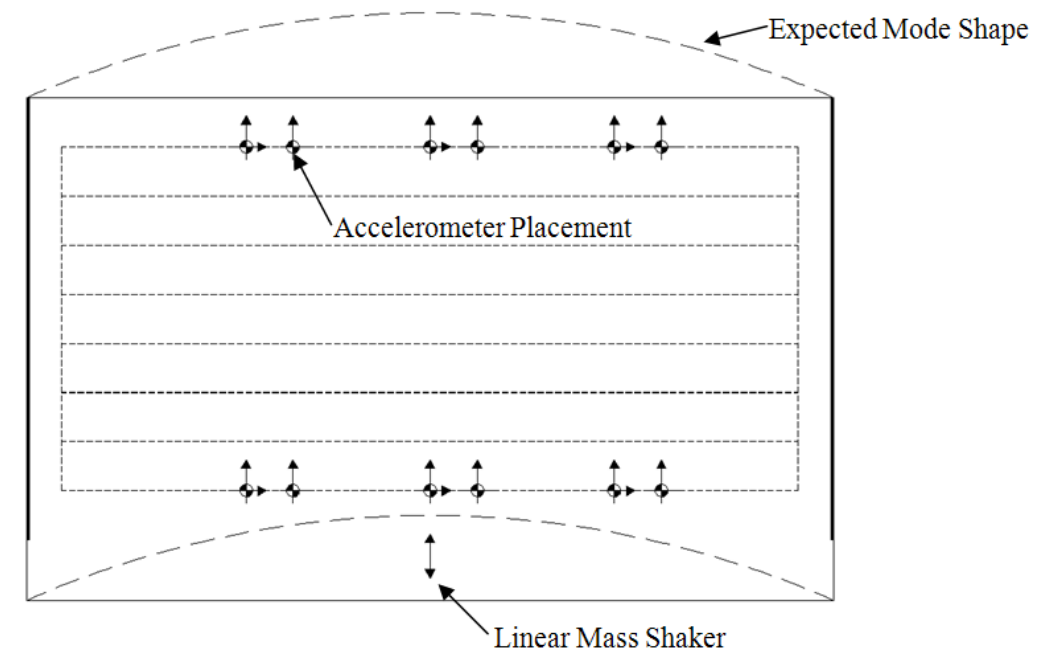

Figure K: Mode 1 Equipment Setup and Expected Mode Shape (Plan View) Source: Jacobsen (2011) 
For the first mode, the shaker was placed at the center of the diaphragm to maximize the simple bending of the diaphragm. The center of the diaphragm was also a node point for the second mode, assumed to be double bending, and so would minimize the participation of Mode 2 .

Accelerometers were placed at the middle and quarter points of the diaphragm, as seen in Figure L on the following page, to record the behavior of the building. Accelerometers were also placed at the edge of the building to determine whether the accelerations at the concrete shear walls were zero. Verifying that the accelerations were approximately zero confirmed that the diaphragm was accommodating the majority of the deformation, just as the Freeman, Searer, and Gilmartin (2002) suggested.

Based on the sweep, the first natural frequencies of the RB and URB were 3.35 $\mathrm{Hz}$ and $2.63 \mathrm{~Hz}$ respectively. For the mode shape testing, the shaker was set to the first natural frequency, and accelerometers were placed at the east quarter point while five recordings were taken. To map the shape of the mode, tt was important to determine whether the various points along the diaphragm were in phase with each other. To check the phase of the middle point, accelerometers A \& $\mathrm{C}$ were left at the quarter point and accelerometer B was moved to the middle point. Once in place, the phase of the three accelerometers was compared to determine whether the locations moved together or opposite from each other. This "leap-frog" method was always used before moving the accelerometers to the next point and when determining whether the north side and south side of the diaphragm acted with or without each other. With most buildings the north 
and south side would be assumed to act in unison, however with the large sawtooth, the diaphragm could have been considered largely discontinuous, so it was possible that the two sides would not act as one solid diaphragm. The "leap-frog" method of testing was confirmed that the north and south sides did act in phase for the first mode.

For the second mode, the shaker was placed at quarter points: the west quarter point for the RB and the east quarter point for the URB, to excite double bending. Accelerations were taken at the same points as the first mode. Figure L below shows the equipment placement as well as the expected shape.

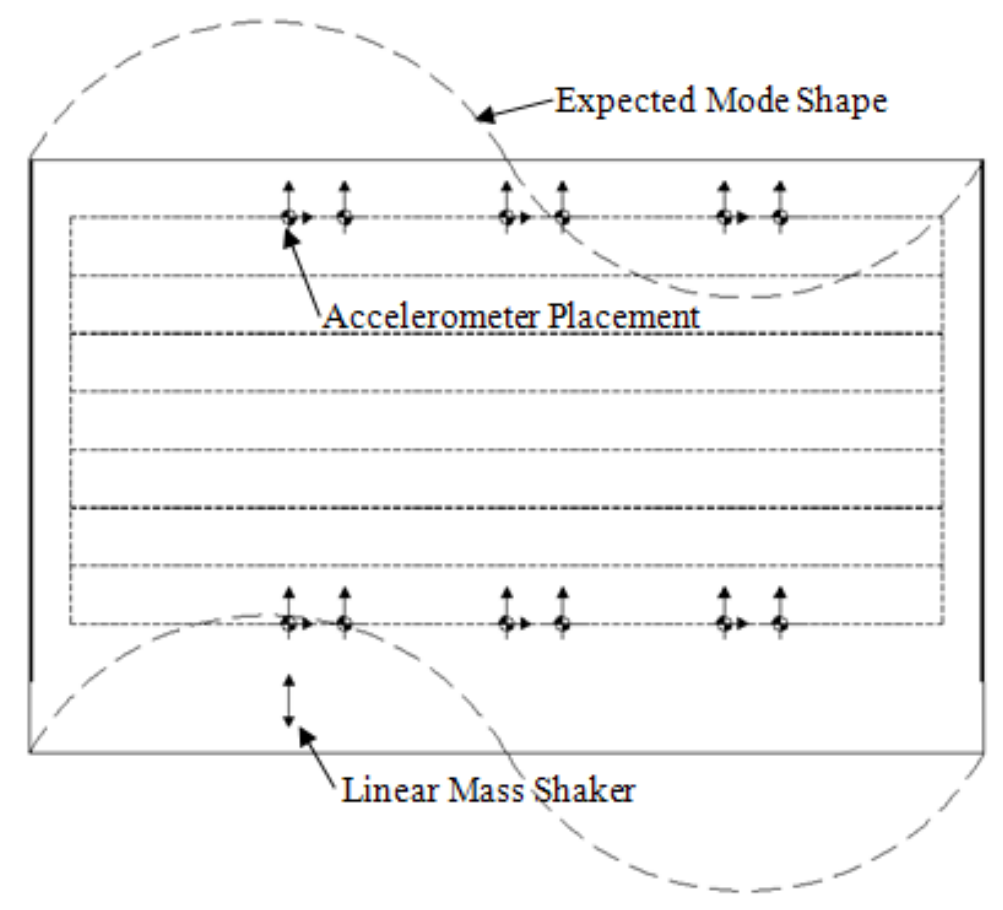

Figure L: Mode 2 Equipment Setup and Expected Mode Shape (Plan View) Source: Jacobsen (2011)

Once in place, the shaker was set to the second natural frequencies found from the sweep, $5.58 \mathrm{~Hz}$ for the RB and $6.18 \mathrm{~Hz}$ for the URB. The accelerations were recorded in 
the same manner as Mode 1, with at least five accelerations recorded at each point and with special attention to the phase angle of each location.

The mode shapes of the RB and URB resemble a beam due to the flexible wood diaphragm. The first two unswept modes of the unretrofit building are shown in Figures $\mathrm{M}$ and $\mathrm{N}$ below.
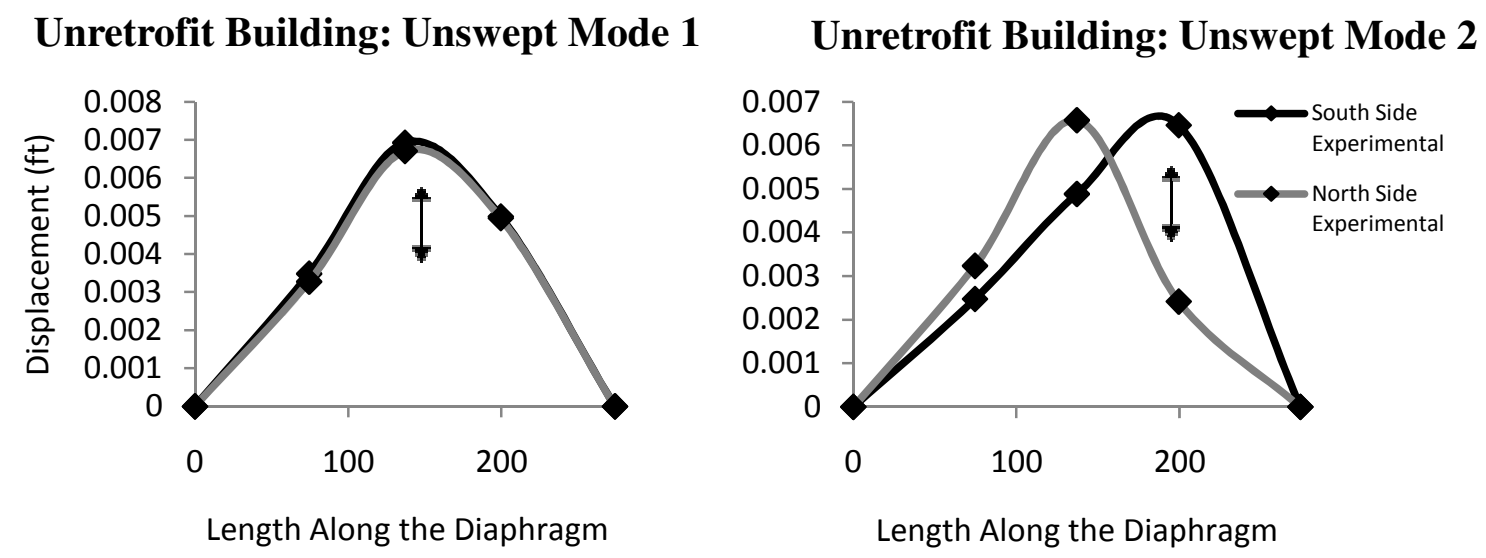

Figures M \& N: Unswept Mode 1 (Left) and Mode 2 (right) of the Unretrofit Building

Source: Jacobsen (2011)

Figures $\mathrm{M}$ and $\mathrm{N}$ plot roof displacement in relation to the position along the diaphragm to show the mode shape found during testing. The double arrow in the figures indicates where the shaker was placed to excite the mode shape, and the two lines represent the shape of the north and south side of the diaphragm. The modes shown in Figures $\mathrm{M}$ and $\mathrm{N}$ are orthonormalized, but unswept, so while Mode 1 appears in its final form, Mode 2 is hardly discernible.

In Figure M, it is apparent that the north and south sides of the building were moving together in a single-bending shape with the maximum displacement in the 
middle. It should be noted that in both Figures $\mathrm{M}$ and $\mathrm{N}$ only the five points with diamond markers were recorded points. The line that connects the points is a spline to connect the points, so aside from those five points, the mode shape is assumed.

Mode 2 was polluted with other modes, and it was necessary to sweep Mode 1 out of it. In this thesis, it was assumed that the first mode was pure and so could be swept out of mode 2. In Figure $M$ there was a clear asymmetry in the mode shape, with the right quarter point higher than the left quarter point. If Mode 1 were truly a pure mode it should be symmetrical about the center of the diaphragm. This asymmetry suggests that other modes were participating in Mode 1 which made sweeping Mode 1 out of Mode 2 less successful than had Mode 1 been pure.

Once the mode shapes were mapped the data was processed to extract the pure mode. Due to modal participation from other modes, the raw data gathered was polluted, and the other modes were swept using the Gram-Schmidt Orthogonalization equation

$$
\Phi_{2}{ }^{\prime}=\Phi_{2}-\frac{\Phi_{1}^{T} M \Phi_{2}}{\Phi_{1}^{T} M \Phi_{1}} \Phi_{1}
$$

where

$$
\begin{aligned}
& \Phi_{2}^{\prime} \text { is the pure mode shape, } \\
& \Phi_{2} \text { is the polluted mode shape, } \\
& \Phi_{1} \text { is the mode to be swept out, and } \\
& \Phi_{1}{ }^{\mathrm{T}} \mathrm{M} \Phi_{2} / \Phi_{1}{ }^{\mathrm{T}} \mathrm{M} \Phi_{1} \text { is the percent of the mode being swept out. }
\end{aligned}
$$

In order to use Equation 2, it was assumed that Mode 1 was the pure mode and that mode 1 must be swept out of the higher modes. Mode 1 was assumed to be the pure 
mode because it did resemble the expected mode shape, suggesting that there was little pollution from higher modes. This assumption, that lower modes participate in higher modes but not the reverse, was necessary to begin the process of sweeping modes. For the purposes of this thesis, Mode 1 was assumed to be the pure shape and was then swept out of mode 2. The limitation of this assumption is that higher modes do in fact participate in lower modes, but it was impossible to sweep out a higher mode since the shape was unknown. Without the pure shape of the higher mode it is not possible to determine to what extent the higher mode is polluting the lower mode.

This concept of modal participation and modal sweeping is more easily explained with a theoretical example of a beam with three modes: single bending, double bending and triple bending as shown in Figure $\mathrm{O}$ on the following page. Assume that during testing of this beam, Mode 2 was polluted with participation from Modes 1 and 3. The shape of polluted Mode 2 is shown in Figure $\mathrm{P}$ on the following page. 


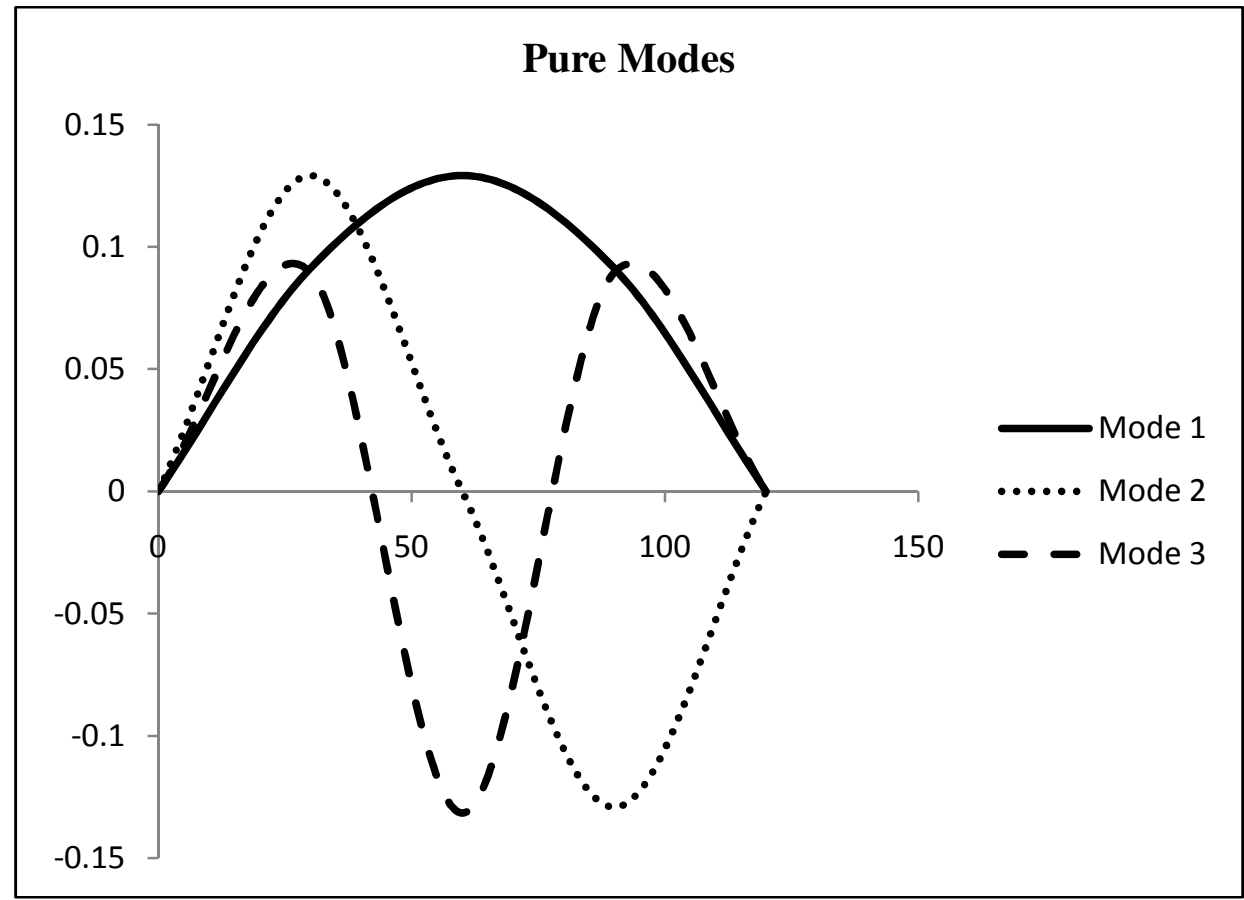

Figure O: Pure Modes 1, 2, and 3 Used in Theoretical Example Source: Jacobsen (2011)

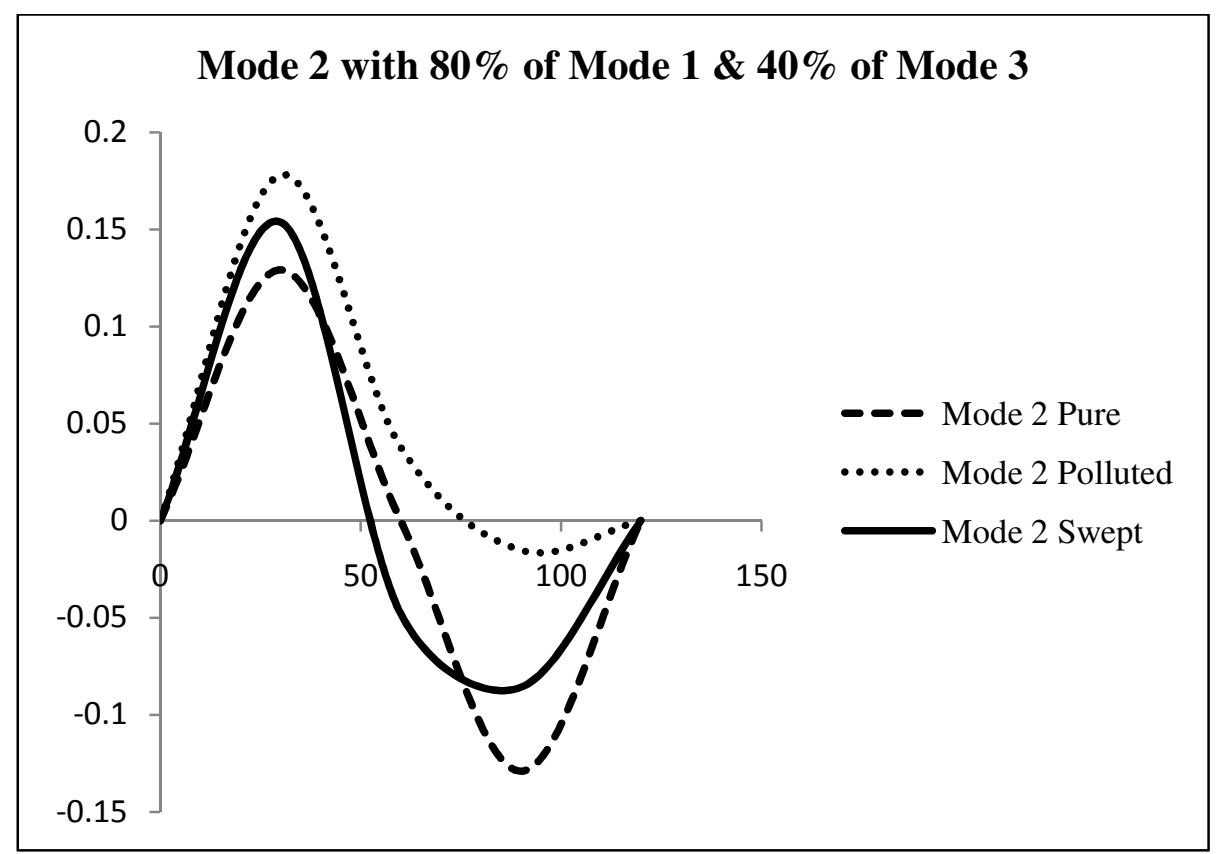

Figure P: Polluted Mode 2 Used in Theoretical Example Source: Jacobsen (2011)

Forced Vibration Testing of Pre- and Post- Retrofit Buildings 
Figure P illustrates the many shapes that Mode 2 can appear as during testing for a mode depending on the amount of modal pollution. The pure Mode 2 is shown as a dashed line, the polluted Mode 2 is shown as a dotted line, and the Mode 2 after Mode 1 was swept from it is shown as a solid line.

In Figure P, it becomes clear that a modal participation from other modes can obscure the pure shape of the mode. The pure Mode 2 is zero at the center of the beam, but the polluted Mode 2 shows a positive value. The pure Mode 2 has a positive and negative peak of equal value, whereas the polluted mode has a higher positive peak and a shallow negative peak. Also illustrated in Figure $\mathrm{P}$ is Mode 2 after Mode 1 has been swept from it. Again the inflection point of Mode 2 shifts due to the pollution of other modes, in this case pollution from Mode 3. The Mode 2 swept shape is important to note as it illustrates how the mode shapes of the buildings analyzed in this thesis may be impure due to higher modal participation.

Mode 1 was pure enough for the purposes of this thesis and clearly participated in Mode 2. In Figure $\mathrm{N}$ on the page 25, it is obvious that Mode 2 resembles Mode 1, indicating a large amount of participation. When performing the Gram-Schmidt sweeping method, the participation from Mode 1 in Mode 2 was calculated to be $82 \%$. So despite Mode 1 being impure, sweeping it from Mode 2 did improve the mode shape, as seen in Figure Q following page. 


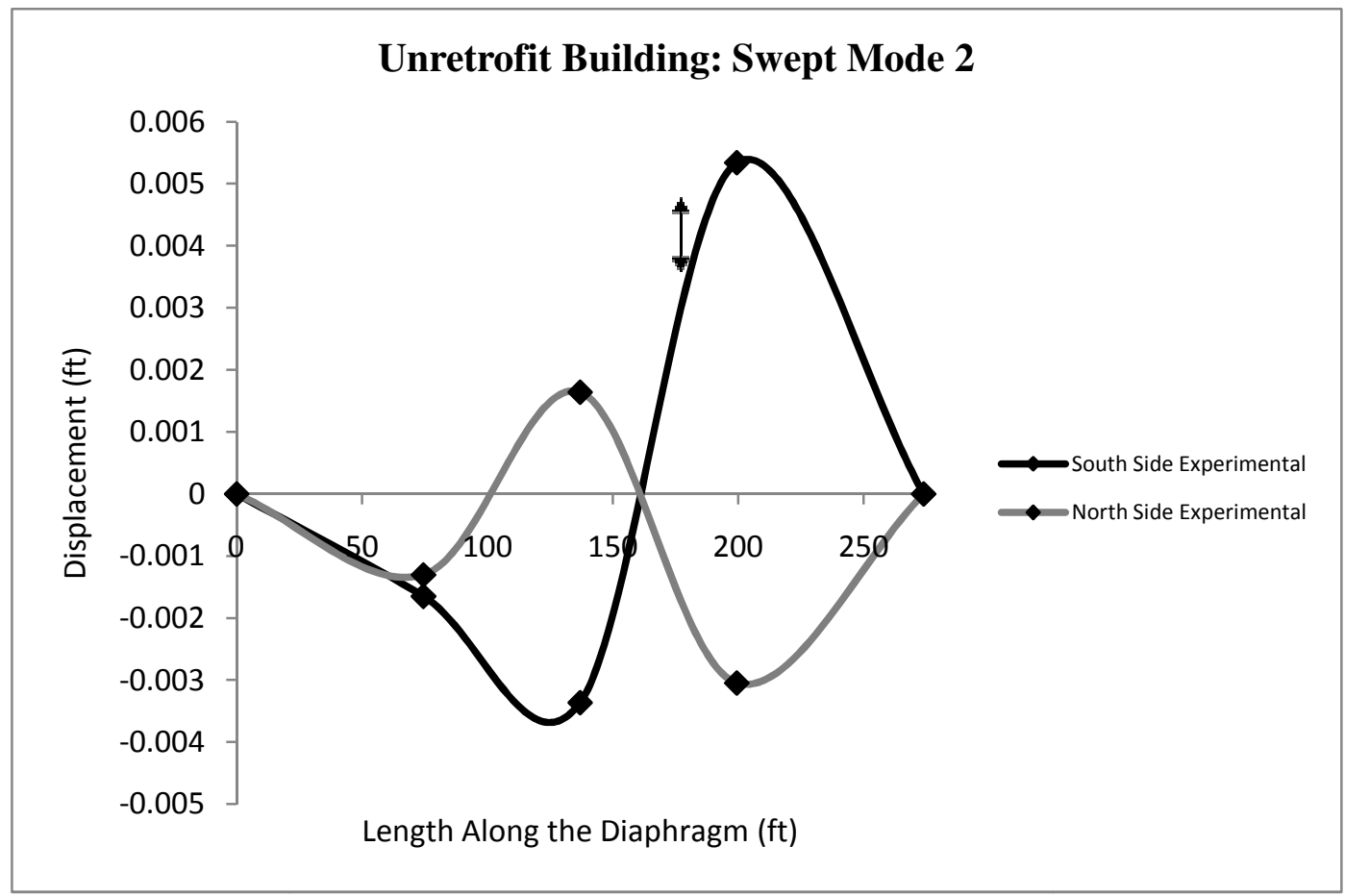

Figure Q: Swept Mode 2 of Unretrofit Building

Source: Jacobsen (2011)

Figure Q shows the two sides of the diaphragm moving opposite from each other and though the shape does not resemble Mode 1 any longer, the shape is not in pure double bending with the inflection point located at the center. Also shown in Figure Q is the two sides of the diaphragm moving opposite to each other. The shape shown in Figure Q could be attributed to several theories; different fixity at the ends of the diaphragm, varying mass or stiffness along the diaphragm, modal pollution from higher modes, or unaccounted flexibility in the diaphragm. Due to the complexity of the last two theories, modal pollution and flexibility in the diaphragm, they will be discussed in more depth.

With modal sweeping, even if it is assumed that Mode 2 is only polluted with Mode 1, sweeping an impure Mode 1 from Mode 2 will not yield perfect results, and the 
clarity of Mode 2 is further obscured when higher modes, Mode 3 and Mode 4, participate. As shown in Figure $\mathrm{P}$ for the theoretical beam example, sweeping Mode 1 from Mode 2 helps the shape but Mode 2 still looks distorted due to the higher modes. In fact, the swept Mode 2 in Figure P resembles the mode shapes shown in Figure Q, with the node shifted from center. It is highly probable that contribution from other modes distorted the shape of Mode 2, shifting the inflection point from the center.

Aside from higher modal participation, an unaccounted flexibility in the diaphragm could have yielded results similar to those tested. According to the shape shown in Figure Q, the two sides of the diaphragm are moving in opposition to each other. Since it is unlikely that the steel wide flanges are stretching and compressing to allow for this shape, it is more probable that there is flexibility in the connections between the roofing membrane and the actual steel frame beneath. The roof connection is shown in Figure $\mathrm{R}$ on the following page. 


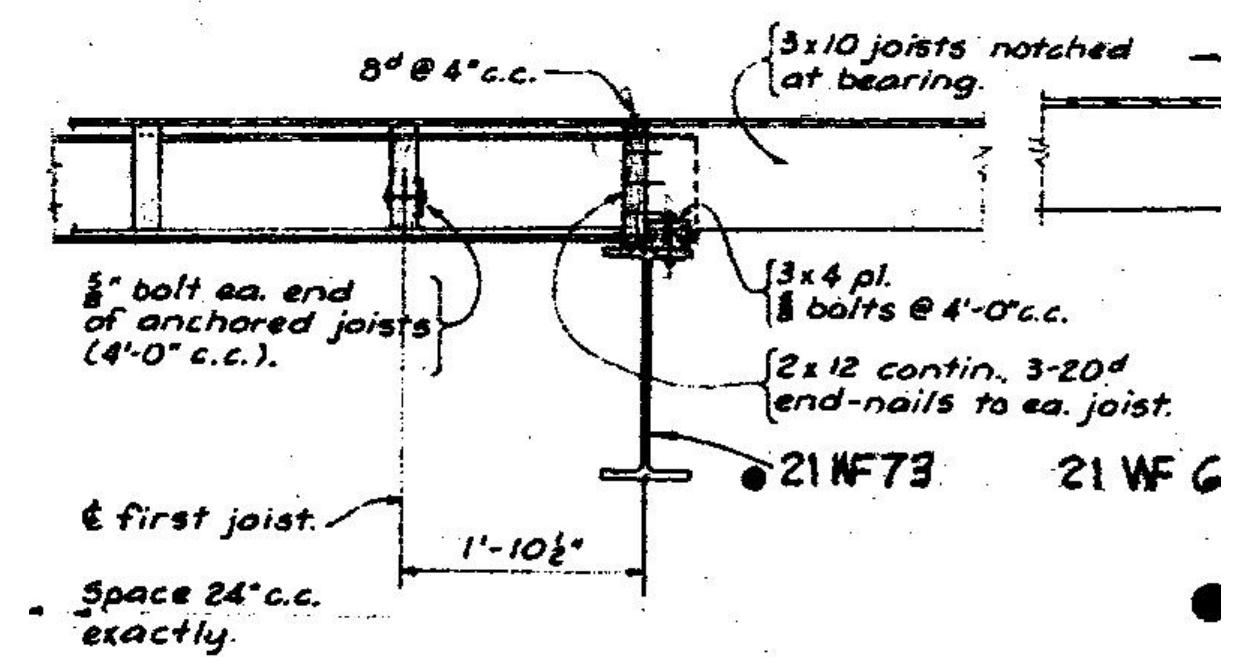

Figure R: Cross Section of Existing Roof

Source: Structural Plans of Existing Building (1959)

The load path through the roof includes multiple connections; the plywood is nailed to a $3 \times 10$ wood joist that is then end-nailed to a $2 \times 12$ continuous wood member. The $2 \times 12$ wood member is nailed to a $3 \times 4$ sill plate, and the $3 \times 4$ sill plate is bolted through the top flange of the steel beam below. The indirect load path shown in Figure $\mathrm{R}$ could allow for slippage in the connections, which could allow for the roof sides to move opposite each other.

To try and mimic the slippage in the connections, a computational model was created inserting springs between the plywood membrane and the steel frame, in an attempt to model this flexibility. When the springs were stiff, the membrane moved with the steel beams. When the springs were flexible, the membrane rotated on top of the beams as though it were a rigid diaphragm. Neither of these behaviors matched the test 
data, but they do not negate the possibility that unaccounted for flexibility in the diaphragm could explain the results.

Figures $\mathrm{S}$ and $\mathrm{T}$ below show the first and second mode shape, respectively, of the RB. The mode shapes were similar to the URB but the accelerations recorded in the RB were approximately $42 \%$ larger than the URB. The URB had a maximum acceleration of $763 \mu \mathrm{gs}$ at the center of the diaphragm and the RB had a maximum acceleration of 1342 $\mu g s$ at the center of the diaphragm. The differences between the accelerations of the second mode were less significant and only varied $15 \%$, with $1022 \mu$ gs recorded on the $\mathrm{URB}$ and $1210 \mu \mathrm{gs}$ recorded on the RB.

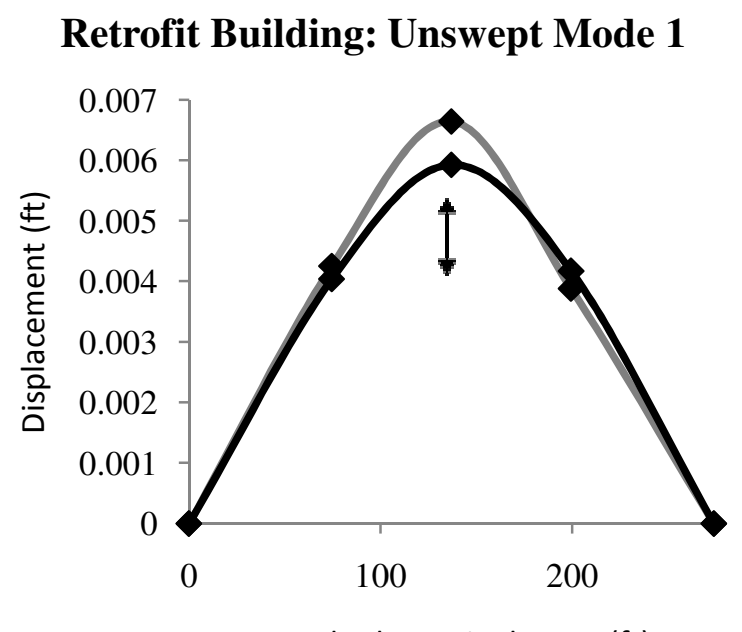

Length Along Diaphragm ( $\mathrm{ft}$ )

\section{Retrofit Building: Unswept Mode 2}

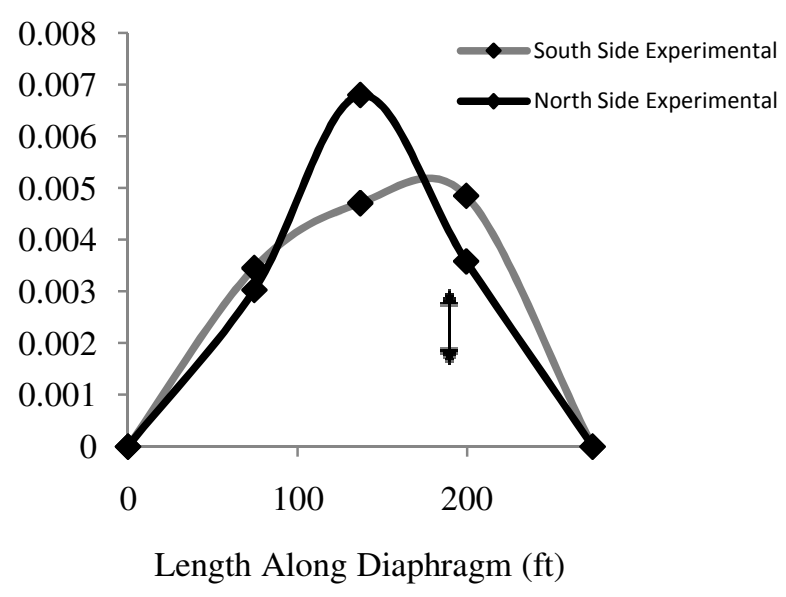

Figure S \& T: Unswept Mode 1 (Left) and Mode 2 (right) of the Retrofit Building Source: Jacobsen (2011)

The first mode shape for the RB appeared much the same as the URB but was more symmetrical. The left and right quarter points were closer to the same acceleration, matching the expected mode shape better than the URB. It should be noted that the lines 
connecting these points are assumptions and that only the points with markers are known. In addition, while testing the RB, a small wood platform on the roof made it impossible to place the shaker in the same position on the RB as where the shaker was placed on the URB. The low platform is built above the roof out of wood $2 \times 4 s$ and is not a part of the building structure; it is thought that the platform was built to support future mechanical equipment. Once all data was collected, the graph was flipped so that the mode shapes of the two buildings could be more easily compared.

Mode 2 for the RB is polluted, similar to the URB, and the sweeping process had to be performed on the data. The swept Mode 2 is displayed below in Figure U.

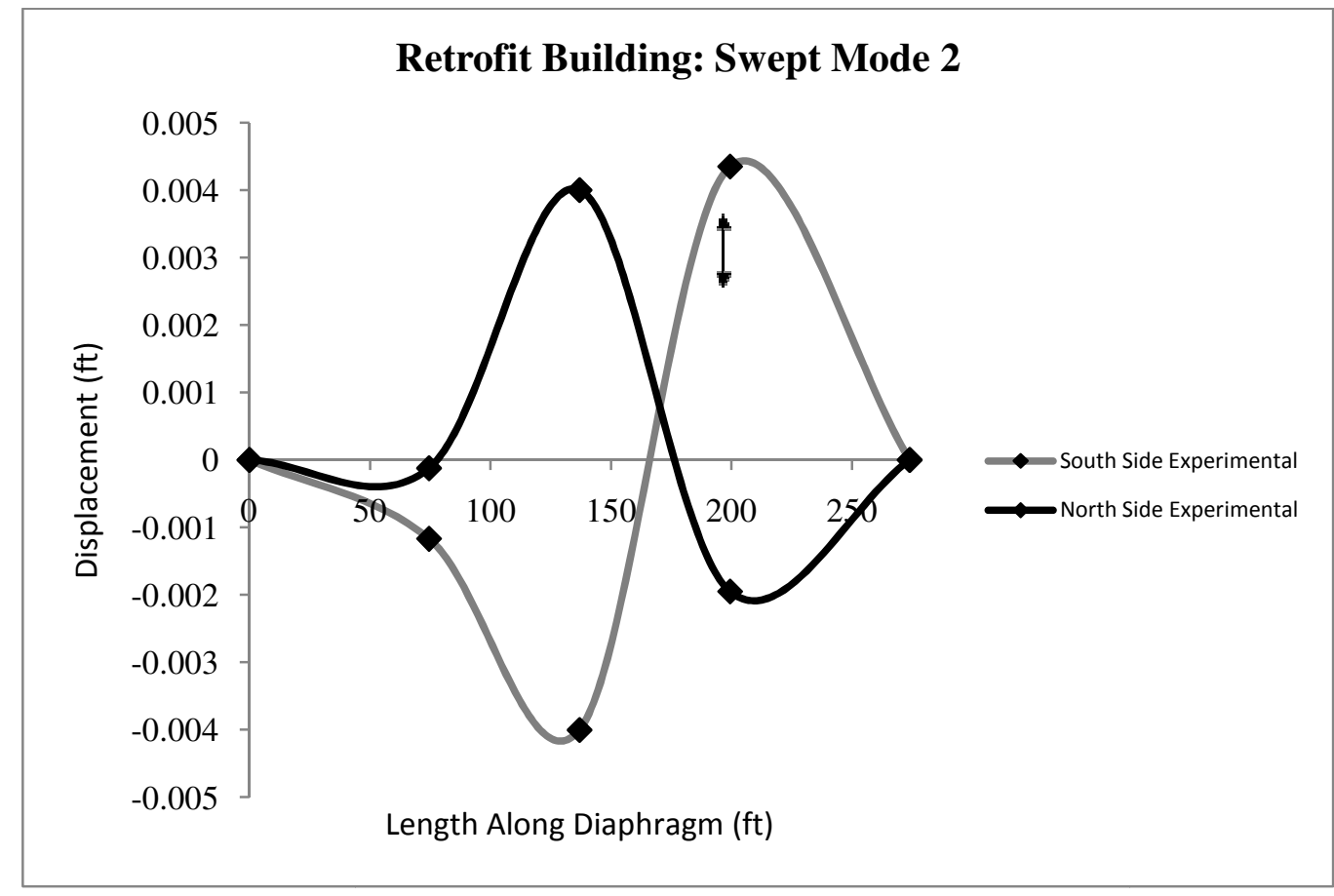

Figure U. Swept Mode 2 for the Retrofit Building

Source: Jacobsen (2011) 
Figure U shows that Mode 2 for the RB is distorted similarly to Mode 2 for the URB shown in Figure Q on page 30. Just as the URB, the Mode 2 for the RB is shifted so that the point at which the displacement is zero is not in the center of the diaphragm. Also, the two sides of the diaphragm are moving opposite to each other. Modal pollution and unaccounted flexibility in the diaphragm are possible reasons for this distortion.

While the mode shapes may have been distorted, they did succeed in confirming that the retrofit did not affect the modal behavior for NS direction. The retrofit primarily consisted of new braces added in the EW direction; braces in the EW direction should not affect the building's behavior in the NS direction as the two directions are orthogonal to each other. The mode shapes for both buildings were nearly identical, with the highest difference in recorded accelerations being $42 \%$ for Mode 1 . This difference in acceleration is explained by the smaller damping ratio in the retrofit building and does not imply that the retrofit affected the NS modal behavior.

\subsection{Damping Ratios}

Both buildings showed clear natural frequencies in the NS direction but none in the EW direction therefore, damping ratios were determined only for the NS modes. Using the frequency-acceleration graphs seen in Figures D and $\mathrm{H}$ on pages 15 and 19 respectively, the damping ratios were found for both buildings using the half-power bandwidth method equation shown on the next page, 


$$
\zeta=\frac{\omega_{b}-\omega_{a}}{2 \omega_{n}}
$$

where $\quad \xi$ is the damping ratio (unitless),

$\omega_{\mathrm{n}}$ is the resonant frequency $(\mathrm{Hz})$, and

$\omega_{\mathrm{b}}$ and $\omega_{\mathrm{a}}$ are the frequencies at $\frac{1}{\sqrt{2}}$ the resonant amplitude $(\mathrm{Hz})$.

Figure V below shows the frequency sweep for the URB in the NS direction and the values used in the half-power bandwidth method outlined in Chopra (2007).

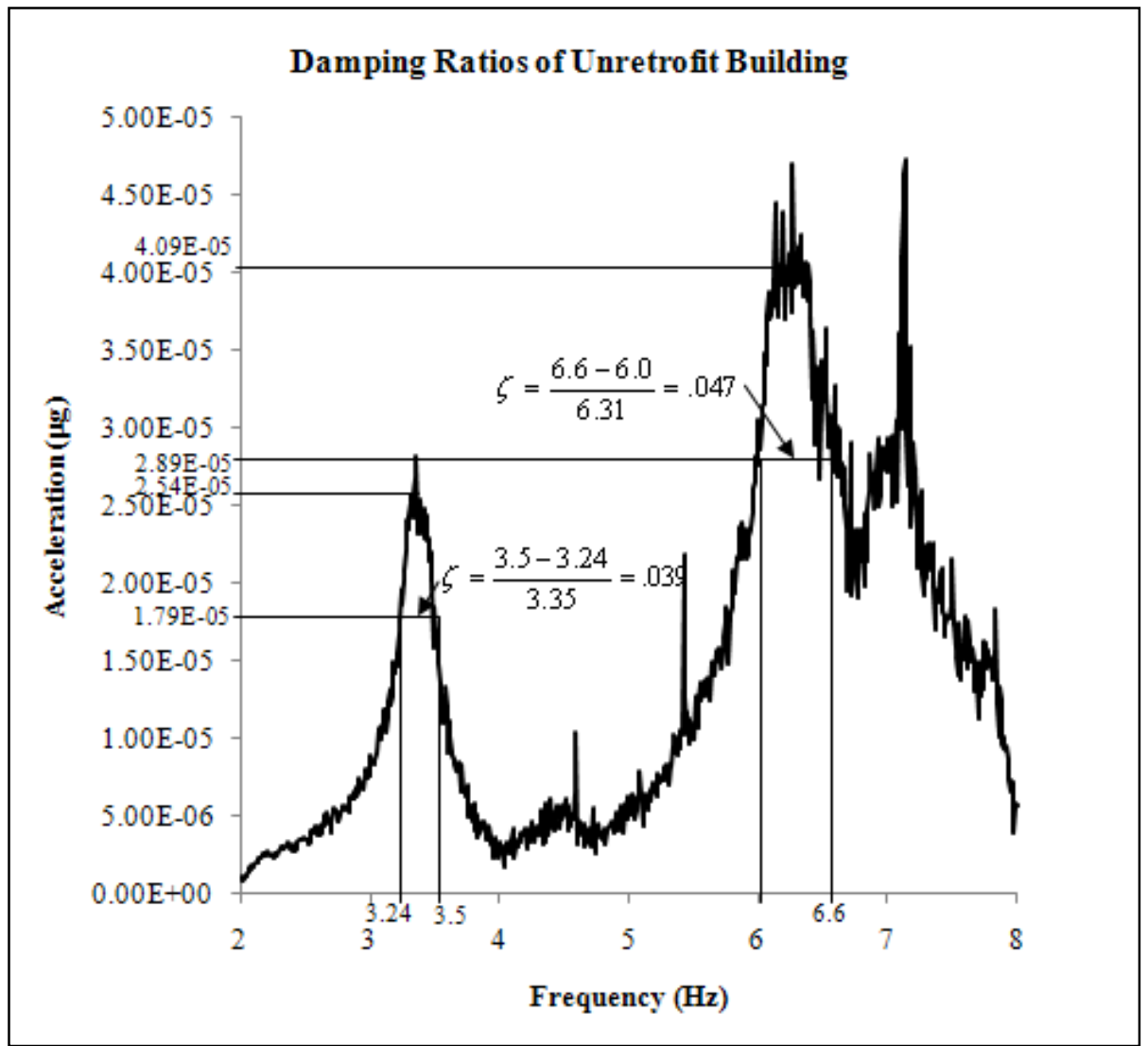

Figure V: Damping Ratios for the Unretrofit Building Source: Jacobsen (2011)

The calculation for the damping ratio is easier to understand by examining Figure V. The first mode had its peak at $3.35 \mathrm{~Hz}$, the natural frequency for Mode 1, and the 
amplitude for that peak is $25.4 \mu \mathrm{gs}$. The width of the peak indicates the amount of damping in the mode; a steep peak on the frequency-acceleration graph indicates little damping, and a broad peak indicated higher damping. The point at which the width of the peak was evaluated was determined by dividing $25.4 \mu \mathrm{gs}$ by $\sqrt{2}$, which equals 17.9 $\mu \mathrm{gs}$ for Mode 1. The two frequencies that correspond to this acceleration on either side of the peak are $3.24 \mathrm{~Hz}$ and $3.5 \mathrm{~Hz}$. Entering these frequencies, along with the natural frequency, into Equation 3, the damping for Mode 1 is calculated to be 3.9\%. The same calculation was performed for Mode 2, which has a damping of $4.7 \%$.

This process was repeated for the retrofit building, the results of which are seen on the below in Figure W. 


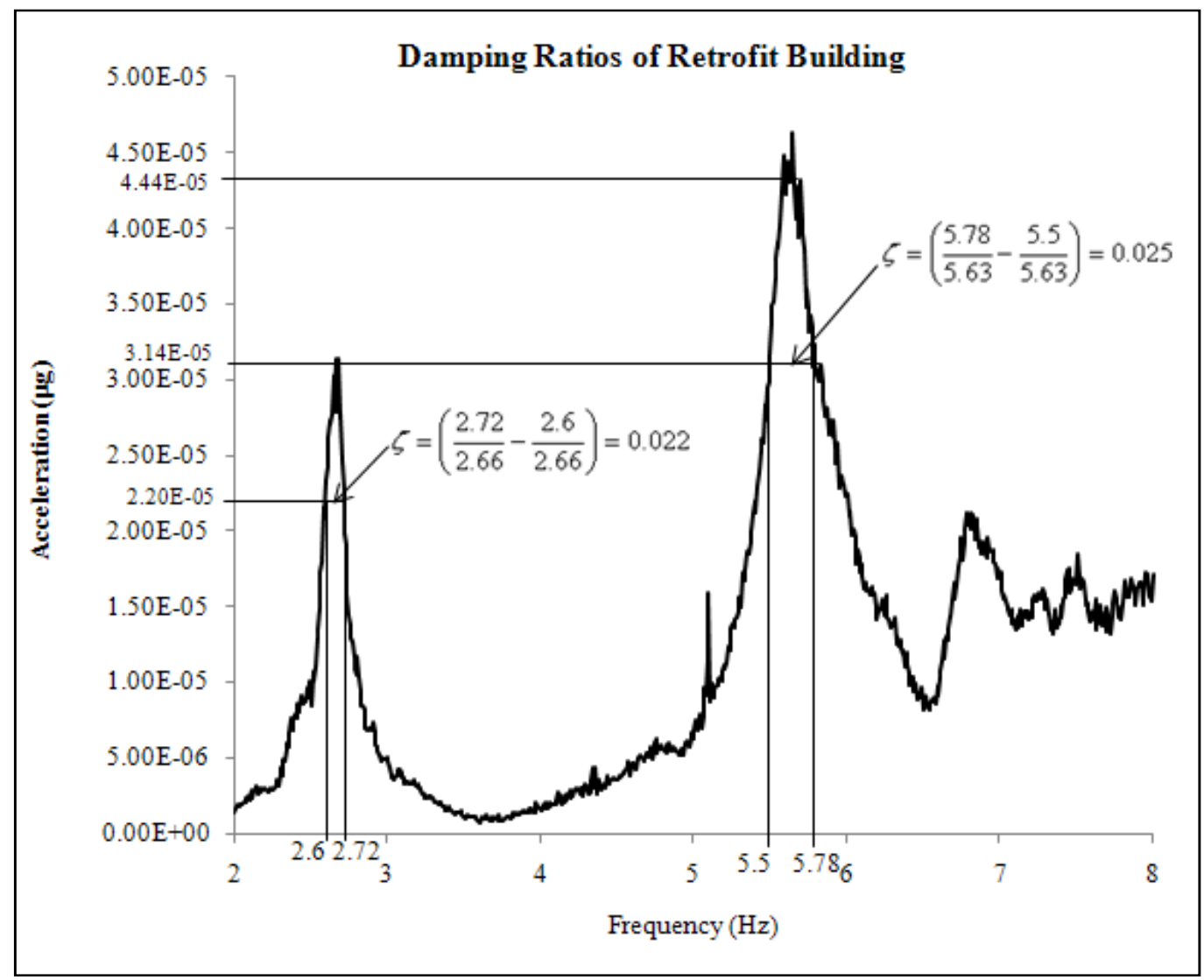

Figure W: Damping Ratios for the Retrofit Building Source: Jacobsen (2011)

The frequency-acceleration graph, as seen in Figure W, shows that the RB has steeper peaks than the URB and therefore the damping is smaller. The damping for the first mode is $2.2 \%$ and the second mode is $2.5 \%$ compared to the $3.9 \%$ and $4.7 \%$ for the URB. Non-structural elements in a building can contribute to the damping of the building and at the time of the testing, the RB was unoccupied and empty of any interior partitions. Also, though the buildings are thought to be nearly identical, it is unknown whether they were built at the same time. Variance in the construction methods and 
materials could also account for the $50 \%$ difference in damping between the two buildings.

\subsection{Summary}

Through FVT and AVT the natural frequencies, mode shapes, and damping ratios of the two buildings in the NS direction was found.

The URB has a natural frequency of $3.35 \mathrm{~Hz}$ for the first mode and $6.31 \mathrm{~Hz}$ for the second mode. The RB has a natural frequency of $2.66 \mathrm{~Hz}$ for the first mode and $5.63 \mathrm{~Hz}$ for the second mode. The natural frequencies in the EW direction could not be detected in either building.

The first two mode shapes in NS direction were detected in both buildings. The first mode shape was simple bending of the diaphragm with maximum accelerations detected in the center of the building. The second mode shape was expected to be double bending, but the tested shape shows differential movement between the north and south side of the building. It is possible that the slip between the plywood and the steel frame resulted in a mode shape that appeared to be compressing and stretching. The plywood is connected to wood joists that are then connected to the wide flanges so there are multiple connections where that slip could occur. While no computational model showed this behavior, it is still a possible explanation.

Another plausible explanation for Mode 2's shape is higher model pollution. A third peak on the FVT graph close to the second mode suggests the third mode is close to the second, making it more likely to interfere with the second mode. As shown in Figure 
$\mathrm{Q}$ in the theoretical example, interference from a higher mode could distort the shape of the second mode, explaining the shape found during testing.

The damping ratios for both buildings were also determined using the forced vibration results in the NS direction. The unretrofit building had 3.9\% damping in Mode 1 and $4.7 \%$ in Mode 2. The retrofit building had 2.2\% damping in Mode 1 and $2.5 \%$ damping in Mode 2.

From the testing it is apparent that the retrofit does not affect the NS modes. The natural frequency shifts down between the URB and the RB suggesting an increase in mass not stiffness. Since the braces should only stiffen the EW direction, this downward shift aligns with the prediction. Also, the URB had no gravel on the roof while the RB had several inches of gravel; this could account for the increase in mass. In addition to the NS frequencies not increasing between buildings, the mode shapes of both buildings match closely, indicating again that the new braces do not affect the NS direction. 


\subsection{COMPUTATIONAL MODELING}

After the experimental data was gathered, the natural frequencies obtained from the vibration testing were compared to the natural frequencies of computational models. The two buildings were complex so the comparison process began with simple models that could describe the building behavior. Subsequent comparisons used increasing model complexity. By incrementally increasing the complexity of the model, the effects of the different modeling assumptions on the building behavior were identified. During the modeling process it became clear that the predicted mode shapes remained similar through all iterations, simple bending of the diaphragm for Mode 1 and double bending of the diaphragm for Mode 2, therefore the focus centered on comparing the natural frequencies not the mode shapes. The modeling process was broken into two main categories: hand calculations and computational modeling.

\subsection{Hand Calculations}

Freeman et al. (2002) state that the first mode of a Rigid-Wall/Flexible-Diaphragm (RW/FD) building is governed by the deflection of the diaphragm in beam-like-bending action. This perspective of viewing the diaphragm as a deep, thin beam warrants using Timoshenko's equations for the natural frequency of a simply supported beam (Rao, 2004). In Rao, (2004) several equations are considered for finding the natural frequency of a beam depending on whether rotary inertia, shear deformation, or neither. The equations that Timoshenko's beam theory produces: 


$$
\omega_{n}^{2}=\frac{\alpha^{2} n^{4} \pi^{4}}{l^{4}\left(1+\frac{n^{2} \pi^{2} r^{2}}{l^{2}}\right)},
$$

Eq. 4

where

$\omega_{\mathrm{n}}$ is the natural frequency $(\mathrm{rad} / \mathrm{s})$,

$\mathrm{E}$ is the modulus of elasticity (ksi),

I is the moment of inertia $\left(\mathrm{in}^{4}\right)$,

$\rho \mathrm{A}$ is the mass of the building per length of diaphragm $\left(\mathrm{k}^{*} \mathrm{~s} / \mathrm{ft} / \mathrm{ft}\right)$, $\mathrm{n}$ is the Nth mode,

1 is the length of the diaphragm (in),

$r^{2}$ is the radius of gyration squared (in), and

$\alpha^{2}$ is the modulus of elasticity multiplied by the moment of inertia and divided by the seismic mass of the building per unit length of diaphragm.

where only rotary inertia was considered,

$$
\omega_{n}^{2}=\frac{\alpha^{2} n^{4} \pi^{4}}{l^{4}\left(1+\frac{n^{2} \pi^{2} r^{2}}{l^{2}} \frac{E}{k G}\right)}
$$

where $\quad \mathrm{k}$ is the shear coefficient for the shape (unitless) and

$\mathrm{G}$ is the shear modulus.

where only shear deformation was considered, and

$$
\omega_{n}^{2}=\frac{\alpha^{2} n^{4} \pi^{4}}{l^{4}}
$$

where neither rotary inertia nor shear deformation was considered. 
The diaphragm was modeled in two ways, as a solid beam 5/8" thick and $170.5^{\prime}$ deep; and as a beam with a hole in it the size of the sawtooth. Practical engineering estimates considering the weight of the plywood, gravel, roofing, beams and half the height of the columns and walls, were made when calculating the mass for the building. The modulus of elasticity, $\mathrm{E}=1000 \mathrm{ksi}$, and shear modulus, $\mathrm{G}=417 \mathrm{ksi}$, of 5/8" plywood were used for the calculations. Mechanical properties of the plywood were obtained from APA (1998) assuming S-1 grade level and dry conditions since the grade of the plywood was not specified in the plans. It is also unknown how age has affected the strength of the wood. All three equations were used for both beam models and compared to the vibration results found in field as shown below in Table 1 below.

Table 1: Hand Calculation Results for NS Direction Source: Jacobsen (2011)

\begin{tabular}{|l|c|c|c|}
\hline Model Description & $\begin{array}{c}\text { Model } \\
\text { Frequency (Hz) }\end{array}$ & $\begin{array}{c}\text { Tested } \\
\text { Frequency (Hz) }\end{array}$ & \% Diff \\
\hline Hand Calculations for NS Direction & 2.29 & 3.35 & $31.6 \%$ \\
\hline $\begin{array}{l}\text { Simply supported beam with gross } \\
\text { section properties of the plywood. } \\
\text { (Unretrofit) }\end{array}$ & 1.70 & 3.35 & $49.3 \%$ \\
\hline $\begin{array}{l}\text { Simply supported beam with reduced } \\
\text { section modulus for hole in diaphragm } \\
\text { (Unretrofit) }\end{array}$ & & & \\
\hline
\end{tabular}

The second column in Table 1 shows the predicted frequencies for the NS direction assuming the diaphragm behaves like a flexible beam. The third column shows the first natural frequency obtained from testing. It is important to note that the predicted frequencies were compared to the frequencies of the URB found during testing. The retrofit did not affect the NS modes, but the two buildings did have different masses due 
to the gravel roofing material on the RB. The mass of the URB was used in the hand calculations and so was compared to the NS frequencies of the URB.

Finally, the fourth column shows the percent difference between the frequencies obtained analytically and the frequencies obtained through testing. The percent difference found between the model frequency and the test frequency can be applied to the RB. The percent difference between the frequencies increased when the diaphragm was modeled as a beam with a hole in it, suggesting that the diaphragm acts as a solid unit despite the sawtooth. Upon observing the percent difference of $31.6 \%$, it was concluded that the simple hand calculation was a fair predictor of the natural frequency considering the simplicity of the calculation. The simple beam model indicates that more than just the membrane contributes to the stiffness of the diaphragm; therefore, a more complicated model was needed to replicate the modal behavior of the building.

While the diaphragm in the NS direction acted like a beam, both experimentally and computationally, the diaphragm in the EW direction acted more like a rigid diaphragm. This rigidity was expected considering the $0.63: 1$ aspect ratio of the diaphragm was well below the code defined 3:1 ratio for flexible diaphragms. This aspect ratio, coupled with the lack of stiff shearwalls in the EW direction, indicated that the relative rigidity of the diaphragm was closer to the rigidity of the lateral system and therefore the diaphragm did not behave like a flexible diaphragm. Consequently, the natural frequency in the EW direction was calculated as though the diaphragm were rigid, only considering the columns and out-of-plane stiffness of the two shearwalls. 
The first computational model for the EW direction accounts for the out-of-plane stiffness of the walls only. The second computational model added the stiffness of the four moment frames. Then the third and final hand calculation includes the stiffness of the new braces in order to predict the frequency of the retrofit building. The results for these hand calculations are shown in Table 2 below.

Table 2: Hand Calculation Results for EW Direction

Source: Jacobsen (2011)

\begin{tabular}{|c|c|c|c|}
\hline Model Description & $\begin{array}{c}\text { Model } \\
\text { Frequency }(\mathrm{Hz})\end{array}$ & $\begin{array}{c}\text { Tested } \\
\text { Frequency }(\mathrm{Hz})\end{array}$ & $\%$ Diff \\
\hline \multicolumn{4}{|l|}{ Hand Calculations for EW Direction } \\
\hline $\begin{array}{l}\text { Rigid diaphragm with two cantilever } \\
\text { columns to model out-of-plane behavior } \\
\text { of the shearwalls. } \\
\text { (Unretrofit) }\end{array}$ & 2.43 & $\mathrm{~N} / \mathrm{A}$ & $\mathrm{N} / \mathrm{A}$ \\
\hline $\begin{array}{l}\text { Rigid diaphragm with two cantilever } \\
\text { columns and four moment frame lines. } \\
\text { (Unretrofit) }\end{array}$ & 2.67 & $\mathrm{~N} / \mathrm{A}$ & $\mathrm{N} / \mathrm{A}$ \\
\hline $\begin{array}{l}\text { Rigid diaphragm with two cantilever } \\
\text { columns, four moment frame lines and } \\
8 \text { braces. } \\
\text { (Retrofit) }\end{array}$ & 5.61 & $\mathrm{~N} / \mathrm{A}$ & $\mathrm{N} / \mathrm{A}$ \\
\hline
\end{tabular}

Though Table 2 does not show a comparison between tested frequencies and analytical frequencies, the values do contribute to the mode shape prediction. The first two models represent the URB and those models predict frequencies near $2.5 \mathrm{~Hz}$. The third model represents the RB with the braces and predicts a natural frequency of 5.61 Hz. This large shift in natural frequency suggests that once the braces are added, the diaphragm no longer behaves as a rigid diaphragm. The significant increase in the LFRS system stiffness indicates that the diaphragm is no longer relatively stiff and so bends 
more like a beam, despite the aspect ratio. This change in modal behavior is also observed in the computational modeling discussed later in this section.

\subsection{Computational Modeling}

The initial computer modeling consists of a simple membrane model of the diaphragm. The membrane modeling is similar to the hand calculations for the beam models and is an appropriate model to begin with based on the comparisons of the hand calculations to the testing. The membrane has the dimensions of the diaphragm and is meshed to allow flexibility between the pinned supports along the lines where the shearwalls are located.

Various models with different membrane thicknesses were created in order to observe how different modeling assumptions affect the modal response. It was important to first determine whether the membrane model could have the gross section properties of the plywood, or whether it had to be adjusted to account for the nonlinear behavior of a wood diaphragm.

A flexible wood diaphragm cannot normally be viewed as one continuous member. The diaphragm is composed of multiple plywood panels, nails, and chords, so the deflection of a wood diaphragm is based on the slip and deflection of the multiple components. The deflection of these multiple components leads to a higher deflection than if the diaphragm is assumed to be a solid piece of plywood. Since the connections of the plywood could not be modeled, the membrane was made thinner in order to match the deflection from the diaphragm deflection equations. After analyzing the natural 
frequency associated with each deflection, it was deemed appropriate to use the thickness associated with gross section properties. Due to the low force level used in testing, the plywood diaphragm behaves more as a unit than as individual panels.

The responses of the models are compared to the unretrofit building and are shown below in Table 3 below.

Table 3: Membrane Model Results for the NS Direction

Source: Jacobsen (2011)

\begin{tabular}{|l|c|c|c|}
\hline Model Description & $\begin{array}{c}\text { Model } \\
\text { Frequency (Hz) }\end{array}$ & $\begin{array}{c}\text { Tested } \\
\text { Frequency (Hz) }\end{array}$ & \%Diff \\
\hline Membrane Model NS Direction & 1.088 & 3.35 & $-67.5 \%$ \\
\hline $\begin{array}{l}\text { Simply supported membrane with } \\
\text { reduced thickness to match IBC } \\
\text { diaphragm deflection equation. } \\
\text { Unretrofit) }\end{array}$ & 1.518 & 3.35 & $-54.7 \%$ \\
\hline $\begin{array}{l}\text { Simply supported membrane with } \\
\text { adjusted thickness to account for } \\
\text { multiple steel chords in diaphragm. } \\
\text { (Unretrofit) }\end{array}$ & 2.059 & 3.35 & $-38.5 \%$ \\
\hline $\begin{array}{l}\text { Simply supported membrane model } \\
\text { with gross section properties of } \\
\text { plywood. } \\
\text { Unretrofit) }\end{array}$ & & 3.35 & $-19.0 \%$ \\
\hline $\begin{array}{l}\text { Fix ed-fixed membrane model with } \\
\text { gross section properties of plywood. } \\
\text { Unnretrofit) }\end{array}$ & 2.715 & & \\
\hline
\end{tabular}

None of the membrane models include vertical members or even beams, simply a flat membrane with the properties of the plywood. The initial model's membrane has a reduced thickness so that the displacement of the diaphragm due to a uniform load matches the IBC (2006) diaphragm displacement equation:

Forced Vibration Testing of Pre- and Post- Retrofit Buildings 


$$
\Delta=\frac{5 v L^{3}}{8 E A b}+\frac{v L}{4 G t}+0.188 L e_{n}+\frac{\sum\left(\Delta_{C} X\right)}{2 b}
$$

where $\quad v$ is the maximum shear due to design loads (plf),

$\mathrm{L}$ is the diaphragm length (ft),

$\mathrm{E}$ is the modulus of elasticity of the chord (psi),

A is the area of the chord cross section $\left(\mathrm{in}^{2}\right)$,

$\mathrm{b}$ is the diaphragm width $(\mathrm{ft})$,

$\mathrm{Gt}$ is the panel rigidity through the thickness (psi),

$\mathrm{e}_{\mathrm{n}}$ is the nail or staple deformation (in),

$\Delta$ is the calculated deflection (in), and

$\Sigma\left(\Delta_{\mathrm{C}} \mathrm{X}\right)$ is the sum of individual chord-splice slip values on both sides of the diaphragm, each multiplied by its distance to the nearest support.

This calculation considers nail slip, chord slip, and chord bending in addition to the shear deflection from the plywood. Chord and nail slip are considered to be zero due to the small force of the shaker. The IBC equation allows for the greatest amount of slip and therefore deflection, so the thickness of the membrane is small in order to decrease the stiffness of the membrane and match the IBC deflection. The frequency of the first membrane model, $1.088 \mathrm{~Hz}$, is $67.5 \%$ different from the tested frequency of the unretrofit building. This difference prompted the creation of models that were increasingly stiff. 
The IBC equation assumes the only chords are at the outermost edges of the diaphragm, however, the buildings tested have chords at each frame line. Lawson (2007) expanded on the IBC deflection equation and calls for added stiffness due to reduced chord bending. The diaphragm deflection was recalculated per Lawson (2007) and the thickness of the membrane was increased to match the smaller deflection. Though increasing the thickness to match the deflection given in Lawson's equation increases the frequency to $1.518 \mathrm{~Hz}$, the percent difference remains high at $54.7 \%$. As a result, it was determined that the membrane thickness should not be reduced at all.

The membrane was then modeled with the gross section properties of the plywood. This increases the natural frequency significantly, up to $2.059 \mathrm{~Hz}$, and the percent difference drops to $38.5 \%$, which is almost half of the original membrane model. Though the percent difference is lower, more iterations were crafted to reduce the difference further. It is not realistic to increase the thickness beyond the gross section properties however, it is appropriate to alter the support conditions of the membrane. The previous membrane models have pinned supports similar to those of a simply supported beam, yet the diaphragm appears to be behaving more like a fixed-fixed beam. The stiffness of the concrete shear walls is significant enough to assume that it restrains the diaphragm, similar to a fixed condition. Therefore the final iteration of the membrane models uses a fixed-fixed membrane with gross section properties of the plywood. Changing the support conditions from pinned to fixed raises the natural frequency to $2.715 \mathrm{~Hz}$ and lowers the percent difference to $19 \%$. 
Once the membrane models were completed, it was apparent that the modal behavior of the diaphragm could not be modeled by the plywood membrane alone. Not only are the membrane models too flexible, they are also limited in the mode shapes they can produce. Though the model predicts simple bending in the NS direction, similar to the test data, the model cannot predict any EW modes since the model is restrained in the EW direction. The membrane model is ineffective at predicting the natural frequencies with accuracy and does not yield much insight into the mode shapes of the building. Despite this, the membrane model is useful for determining the correct effective thickness of the membrane, which at the low level of shaking in this thesis, is the gross section properties of the plywood. In common practice, wood diaphragms are modeled with a thinner membrane in order to account for the additional flexibility in the diaphragm due to slip between the plywood panels. It is important to prove that at the low level shaking used in testing, the panels do not slip, and therefore the membrane in the model does not need to be thinner than the gross section properties.

After the membrane model options were explored, a more complex model of the diaphragm was created to further lower the percent difference between the tested and predicted natural frequencies. This next stage of modeling introduces the steel beams, girders, and eventually the sawtooth framing. The lateral-force-resisting system (LFRS) is still excluded so only the members in the plane of the diaphragm affect the stiffness. The goal of the diaphragm models is to explore how the steel framing, most specifically 
the sawtooth framing, affects the behavior of the building. The results of the diaphragm models are shown in Table 4 below.

Table 4: Diaphragm Model With Sawtooth Results

Source: Jacobsen (2011)

\begin{tabular}{|l|c|c|c|}
\hline Model Description & \multicolumn{1}{|c|}{$\begin{array}{c}\text { Model } \\
\text { Frequency (Hz) }\end{array}$} & $\begin{array}{c}\text { Tested } \\
\text { Frequency (Hz) }\end{array}$ & \%Diff \\
\hline Diaphragm Model With Saw tooth NS Direction & \multicolumn{2}{|c|}{} \\
\hline $\begin{array}{l}\text { Membrane model with major } \\
\text { beams and hole in sawtooth location. } \\
\text { Unretrofit) }\end{array}$ & 1.234 & 3.35 & $-63.2 \%$ \\
\hline $\begin{array}{l}\text { Membrane model with major } \\
\text { beams. Sawtooth modeled as a } \\
\text { flat membrane attached at one end. } \\
\text { (Unretrofit) }\end{array}$ & 2.305 & 3.35 & $-31.2 \%$ \\
\hline $\begin{array}{l}\text { Membrane model with major beams } \\
\text { Sawtooth modeled as a slanted } \\
\text { membrane. } \\
\text { (Unretrofit) }\end{array}$ & 1.4015 & 3.35 & $-58.2 \%$ \\
\hline
\end{tabular}

The first diaphragm model includes the major wide flange beams, no joists, and a hole in the membrane where the sawtooth is located. The east and west edges of the diaphragm are fixed rather than pinned to simulate the fixedness of the diaphragm connection to the shearwalls. The first model ignores any stiffness that the sawtooth framing might contribute to the diaphragm and models a hole where the sawtooth is located. The low frequency, $1.234 \mathrm{~Hz}$, and high percent difference, $63.2 \%$, suggests that the sawtooth is not the equivalent of an opening in the diaphragm and does contribute stiffness.

Based on these findings, a simplified version of the sawtooth is explored first. The sawtooth is simplified by not modeling the slanted framing. Instead, the second 
model uses a flat membrane with a reduced thickness to simulate the stiffness of a slanted membrane. On site, the plywood of the sawtooth is slanted, so one edge of the membrane connects with the horizontal plywood of the diaphragm. This effect is simulated by modeling the sawtooth as a horizontal membrane with only one edge connected. The stiffness of the diaphragm does increase and the frequency shifts to $2.305 \mathrm{~Hz}$, as shown in Table 4 on the previous page, and the percent difference decreases to $31.2 \%$.

This attempt to model the sawtooth appears viable, but the next step was to model the sawtooth as it exists on site, with steel framing and slanted plywood. The sawtooth framing consists of slanted wide flanges that connect to the frames below and small tube columns that are also welded to the frame lines. Plywood spans between the wide flanges along the slanted plane, and glass windows occupy the vertical plane. The steel framing is included in the model as is the plywood membrane; the windows are excluded. Modeling the sawtooth as it really is framed makes the diaphragm more flexible than the flat membrane model, and the frequency reduces to $1.402 \mathrm{~Hz}$. The percent difference between this model and the tested frequencies increases to $58.2 \%$.

The diaphragm model does not yield smaller percent differences than the membrane model because of the large discontinuity in the diaphragm due to the sawtooth. Though the membrane models have smaller percent differences, the building is not better modeled with only a membrane. There are too many members ignored in the membrane model for it to be anything other than a stepping stone to a more complete model. The same is true for the diaphragm models. The diaphragm model is limited to predicting NS 
modes, since it is restrained in the EW direction; and the diaphragm does not predict the natural frequencies with accuracy. It was initially assumed that since the mode shape of the building in the NS direction is the diaphragm bending, the LFRS has little to do with the mode shape, but after completing many diaphragm models it becomes clear that the LFRS must affect the modal behavior of the diaphragm and should be included.

The final stage of modeling includes the vertical members, columns and shear walls that support the diaphragm as shown in Figure X.

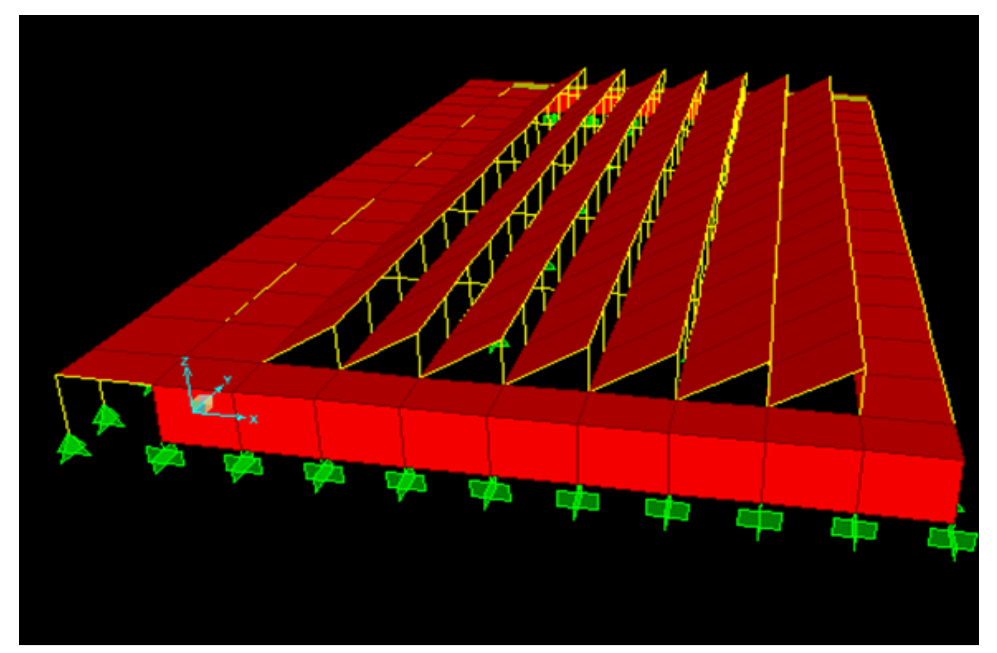

Figure X: Computer Model With Vertical Members Included Source: Jacobsen (2011)

The vertical members provide the rigidity the diaphragm needs to accurately represent the test results. Also by modeling the LFRS, the retrofit scheme can be included in the model and compared to the test results to see whether the effect of the retrofit can be predicted by the computational model. Since the walls extend from the story below and have a thick waffle slab framing into them, the walls are modeled as fixed at the base. The steel columns end at the waffle slab and the connection at their base 
is not stiff enough to suggest a fixed connection, therefore the columns are modeled as pinned at the base. The comparison between the NS natural frequencies of the model to the NS natural frequencies obtained during testing are shown in Table 5 below.

Table 5: 3-D Model Results for NS Direction

Source: Jacobsen (2011)

\begin{tabular}{|c|c|c|c|}
\hline ModelDescription & \begin{tabular}{|c|} 
Model \\
Frequency $(\mathrm{Hz})$
\end{tabular} & \begin{tabular}{|c|} 
Tested \\
Frequency $(\mathrm{Hz})$
\end{tabular} & \%Diff \\
\hline \multicolumn{4}{|l|}{ 3-D Building Mod el:NSDirection } \\
\hline $\begin{array}{l}\text { Building with } 15^{\prime} \text { columns and walls } \\
\text { All beams are modeled. Sawtooth } \\
\text { modeled as a hole in diaphragm. } \\
\text { (Unretrofit) }\end{array}$ & 2.6 & 3.35 & -22.496 \\
\hline $\begin{array}{l}\text { Building with } 15^{\prime} \text { columns and walls } \\
\text { All beams are modeled. Sawtooth } \\
\text { modeled as a slanted membrane. } \\
\text { (Unretrofit) }\end{array}$ & 2.86 & 3.35 & -14.696 \\
\hline $\begin{array}{l}\text { Building with } 13.25^{\prime} \text { columns and walls } \\
\text { All beams are modeled. Sawtooth } \\
\text { modeled as a slanted membrane. } \\
\text { (Unretrofit) }\end{array}$ & 3.23 & 3.35 & $-3.6 \%$ \\
\hline $\begin{array}{l}\text { Building with } 13.25^{\prime} \text { columns and walls } \\
\text { Only major beams are modeled. } \\
\text { Sawtooth modeled as a slanted membrane. } \\
\text { Unretrofit) }\end{array}$ & 3.21 & 3.35 & -4.296 \\
\hline $\begin{array}{l}\text { Building with } 15^{\prime} \text { columns and walls. } \\
\text { All beams, braces, and tension rods } \\
\text { are modeled. Sawtooth modeled as a } \\
\text { slanted membrane. } \\
\text { (Retrofit) }\end{array}$ & 2.57 & 2.63 & $-2.3 \%$ \\
\hline $\begin{array}{l}\text { Building with } 15^{\prime} \text { columns and walls } \\
\text { Only major beams are modeled. } \\
\text { Braces and tension rods included. Sawtooth } \\
\text { modeled as a slanted membrane. } \\
\text { (Retrofit) }\end{array}$ & 2.55 & 2.63 & $-3.0 \%$ \\
\hline $\begin{array}{l}\text { Building with } 13.25^{\prime} \text { columns and walls } \\
\text { Only major beams are modeled. } \\
\text { Braces and tension rods included. Sa wtooth } \\
\text { modeled as a slanted membrane. } \\
\text { (Retrofit) }\end{array}$ & 2.84 & 2.63 & 8.096 \\
\hline $\begin{array}{l}\text { Building with } 13.25^{\prime} \text { columns and walls. } \\
\text { All beams, braces, and tension rods } \\
\text { modeled. Sawtooth modeled as a slanted } \\
\text { membrane. } \\
\text { (Retrofit) }\end{array}$ & 2.86 & 2.63 & 8.796 \\
\hline
\end{tabular}

Forced Vibration Testing of Pre- and Post- Retrofit Buildings 
The first 3-D model is of the RB and includes the shearwalls and the moment frames. Among the diaphragm models, the model with the hole at the location of the sawtooth is too flexible and poorly matches the tested natural frequencies. However, the addition of the LFRS dramatically increases the stiffness of the building so the first model includes the hole to determine whether the combination of the hole and LFRS system matches the tested frequencies. This is a reasonable assumption, since many engineers would discount any load transfer through the sawtooth, however, even with the LFRS, the model is too flexible. The natural frequency of the 3-D model with the hole in the diaphragm is $2.6 \mathrm{~Hz}$, with a percent difference of $22.4 \%$. This percent difference is the largest shown in Table 5 and proves the sawtooth does not act as simply a hole in the diaphragm according to the testing results.

At this stage in the modeling process it became important to look at the story height and the level of the steel girders as they affected the moment frame stiffness; the girders in the two directions are at two different levels as shown in Figure Y below. 


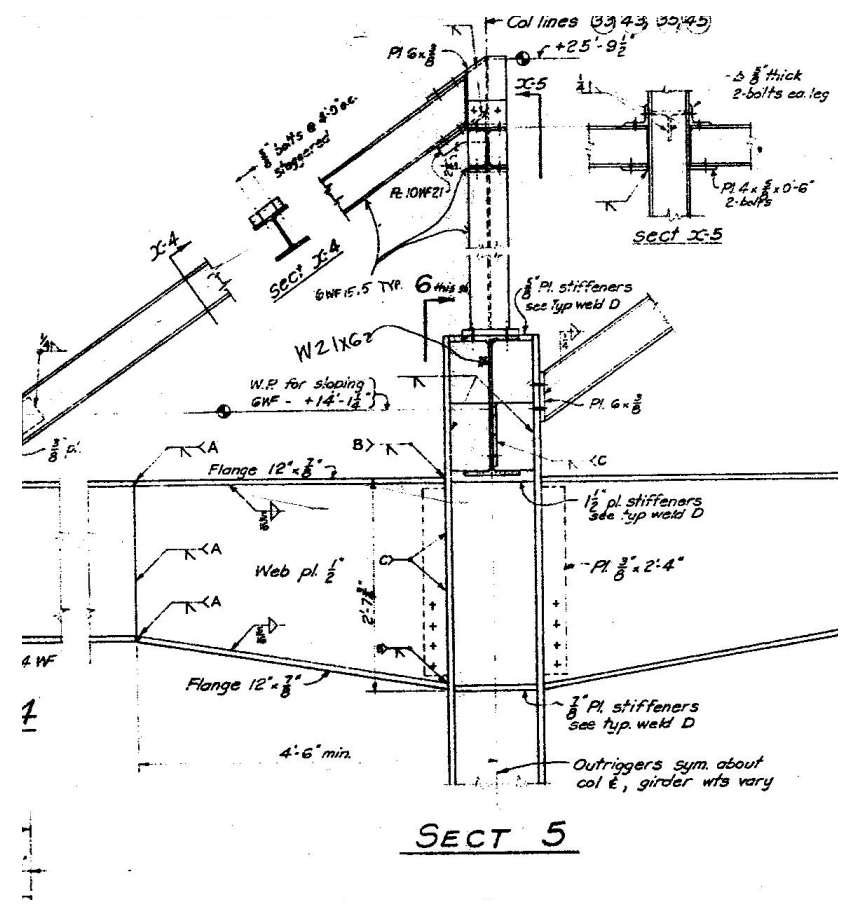

Figure Y: Section Showing Moment Frame Beams at Different Elevations Source: Jacobsen (2011)

As seen in Figure Y, the girders in the EW direction frame on top of the NS

girders and so there are two top-of-steel elevations: $15^{\prime}$ and $13.25^{\prime}$. Due to the complexity of modeling the beams at the different levels and attaching the membrane to the two levels, two models are created with the two different story heights.

The second model shown in Table 5 has a story height of $15^{\prime}$ and also includes the sawtooth framing which helps stiffen the diaphragm. By adding in the sawtooth framing, the natural frequency of the building increases to $2.86 \mathrm{~Hz}$ and the percent difference drops to $14.6 \%$, the lowest of the models thus far. The third model shown in Table 5 is similar to the second except that its story height is 13.25 '. The frequency of the model 
with the lower story height is the closest to the tested frequency, with $3.23 \mathrm{~Hz}$ and a percent difference of $3.6 \%$.

The last model created for the unretrofit building, the fourth shown in Table 5 on page 54 , is identical to the previous model but without wood joists. As expected, the frequency is barely affected by the change and the frequency only drops to $3.21 \mathrm{~Hz}$.

The lower half of Table 5 illustrates the frequencies of the retrofit building models. Most of the changes made for the unretrofit model are made for the retrofit model, but the frequencies are lower due to the increased mass of the retrofit building. Braces have been added to the building, but they do not affect the frequencies in the NS direction.

The retrofit model started at a height of $15^{\prime}$ and includes the sawtooth framing. Because the hole in the diaphragm creates too much flexibility in the unretrofit model, it is not included in the retrofit models. The model with the $15^{\prime}$ roof height and all the beams, matches the tested frequency most closely at $2.57 \mathrm{~Hz}$ and a percent difference of 2.3\%. The small joists are excluded for a second model and this exclusion changes the frequency marginally to $2.55 \mathrm{~Hz}$ and a percent difference of $3.0 \%$. These models are repeated with a lower roof height of 13.25 ', but the change in height stiffens the building so that the frequencies become $2.84 \mathrm{~Hz}$ and $2.86 \mathrm{~Hz}$, exceeding the tested frequency by $8.0 \%$ and $8.7 \%$.

Once the LFRS was modeled, the natural frequencies improved noticeably. As shown in Table 5, the highest percent difference among the 3-D models is $22.4 \%$, much 
lower than the $58.4 \%$ difference in the membrane model. By including the LFRS the computational model is able to confirm the results found in testing.

The natural frequencies found during testing suggest that the retrofit does not affect the modal behavior of the building in the NS direction. This data is supported by the computational models. The natural frequencies of the retrofit building decreased during testing, due to the larger mass of the retrofit building. The RB has a thick layer of gravel roofing material while the URB has a minimal amount. Had the braces affected the NS direction, the frequency would have increased. This frequency shift is also observed in the computational modeling and is shown in Table 5 on page 54. Since the retrofit is primarily focused on the EW direction, the effect on the NS direction should be minimal, and both testing and computational models support that result.

The first NS mode mapped during testing matches the mode from the computational model well. Both the mode shape found during testing and the mode shape from the computational model are single bending with the maximum displacement in the center of the diaphragm. The only difference between the two is that the mode shape from the computational model is symmetrical about the center of the diaphragm, whereas the mode shape from the testing is lopsided as shown in Figure M on page 25. This asymmetry about the center of the diaphragm is likely due to modal participation from higher modes; an issue that is not present in the computational model. In addition to their similar shape, both the testing and the computational model show no change in the 
first NS mode due to the retrofit. Both the testing and the computational analysis suggest the retrofit only affects the EW direction.

The second NS mode shape found in testing does not resemble the computational model to the same degree as the first mode shape. The computational model shows the second NS mode shape as the entire diaphragm in double bending; where the testing shows a shape that is not double bending with two sides of the diaphragm acting in opposition rather than in unison. While Mode 1 may be slightly polluted by modal participation, Mode 2 is hardly recognizable due to the influence of other modes. Figure $\mathrm{P}$ on page 28 shows how the mode shape can be obscured due to the participation of other modes. Also, the closer modes are to each other on the frequency range, the more participation is likely to occur. Figures D and H on pages 15 and 19 both show a peak soon after the second mode, near $7 \mathrm{~Hz}$, which may be the third mode. This potential third mode is close enough to the second mode to suggest it is interfering with the test data.

Computational models were created to simulate unaccounted flexibility, another reason for the obscured Mode 2. Springs were added to allow the plywood membrane to move independently from the steel beams. When the springs became more flexible the membrane began to behave like a rigid diaphragm, translating and rotating as a unit. While the two sides of the diaphragm move in the same direction, even with the springs, one side does not move as much as the other. This does not resemble the test data, and the frequencies are disparate enough from the test data that the model results are not included in Table 5. While unaccounted flexibility can exist in the building diaphragm, it 
is not captured in the models. Another explanation for the difference between the tested Mode 2 and the predicted Mode 2 is modal pollution from higher modes.

Through analysis of the 3-D models in the NS direction it is concluded that a "good" model is a model that accurately replicates the real modal behavior of the building, including major beams and girders, the sawtooth framing, and the LFRS. It is not enough to model just the membrane or even just the roof framing; the entire system has to be modeled before satisfactory results are achieved. However, it is apparent that while the story height does have an effect, the difference is not so large between the two heights that the models become inaccurate. It was also clear that a "good" model does not require minute detailing; the wood joists have little effect on the modal behavior, so only major elements need to be included in the model.

Another advantage of the 3-D models is that they allowed movement in the EW direction and so frequencies can be obtained for that direction. Table 6 on the following page illustrates how the changes to the 3-D model affect the natural frequency in the EW direction. 
Table 6: 3-D Model Results for EW Direction.

Source: Jacobsen (2011)

\begin{tabular}{|c|c|c|c|}
\hline ModelDescription & \begin{tabular}{c|c|} 
Model \\
Frequency $(\mathrm{Hz})$
\end{tabular} & $\begin{array}{c}\text { T eted } \\
\text { Frequency }(\mathrm{Hz})\end{array}$ & \%Diff \\
\hline \multicolumn{4}{|l|}{ 3-D Building Model:E W Direction } \\
\hline $\begin{array}{l}\text { Building with } 15 \text { colvmns and walls } \\
\text { All beams are modeled. Sawtooth } \\
\text { modeled as a slanted membrane. } \\
\text { (Unretrofit) }\end{array}$ & 1.62 & $\mathrm{NA}$ & $\mathrm{N} / \mathrm{A}$ \\
\hline $\begin{array}{l}\text { Building with } 13.25 \text { columns and walls } \\
\text { Atl beams are modeled. Sawtooth } \\
\text { modeled as a slanted membrane. } \\
\text { (Unretrofit) }\end{array}$ & 1.90 & $\overline{\mathrm{NA}}$ & $\overline{\mathrm{N} / \mathrm{A}}$ \\
\hline $\begin{array}{l}\text { Building with } 13.25 \text { colvmns and walls } \\
\text { Only maj or beams are modeled. } \\
\text { Saw tooth modeled as a slanted membrane. } \\
\text { (Unretrofit) }\end{array}$ & 1.86 & $\overline{\mathrm{NA}}$ & $\mathrm{N} / \mathrm{A}$ \\
\hline $\begin{array}{l}\text { Building with } 15 \text { colvmns and walls. } \\
\text { All beams, braces, and tension rods } \\
\text { are modeled. Sawtooth modeled as a } \\
\text { slanted membrane. } \\
\text { (Retrofit) }\end{array}$ & 2.51 & $\overline{\mathrm{NA}}$ & $\mathrm{N} / \mathrm{A}$ \\
\hline $\begin{array}{l}\text { Bvilding with } 15 \text { colvmns and walls } \\
\text { Only maj or beams are modeled. } \\
\text { Braces and tension rods inchded. Saw tooth } \\
\text { modeled as a slanted membrane. } \\
\text { Retrofit) }\end{array}$ & 2.48 & $\overline{\mathrm{NA}}$ & $\mathrm{N} / \mathrm{A}$ \\
\hline $\begin{array}{l}\text { Building with } 13.25 \text { colvmns and walls } \\
\text { Only maj or beams are modeled. } \\
\text { Braces and tension rods inchded. Saw tooth } \\
\text { modeled as a slanted membrane. } \\
\text { (Retrofit) }\end{array}$ & 3.83 & $\overline{\mathrm{NA}}$ & $\overline{\mathrm{N} / \mathrm{A}}$ \\
\hline $\begin{array}{l}\text { Building with } 13.25 \text { colvmns and walls. } \\
\text { All beams, braces, and tension rods } \\
\text { modeled. Sawtooth modeled as a slanted } \\
\text { membrane. } \\
\text { (Retrofit) }\end{array}$ & 3.89 & NA & $\mathrm{N} / \mathrm{A}$ \\
\hline
\end{tabular}

Though there is no tested frequency for comparison, Table 6 does show the change in the natural frequency due to the retrofit. The first model shown in Table 6, the $15^{\prime} \mathrm{URB}$, is the most flexible with a frequency of $1.62 \mathrm{~Hz}$. The lower roof height of $13.25^{\prime}$ in the second model raises the natural frequency to $1.86 \mathrm{~Hz}$. Again, the exclusion of the wood joists lowers the frequency minimally, to $1.86 \mathrm{~Hz}$. Adding the braces does 
increase the frequency to $2.51 \mathrm{~Hz}$, but this number is deceptive as the additional mass of the RB lowers the frequency, while the added stiffness of the braces raises it.

The next iteration of modeling was to lower the retrofit building height to $13.25^{\prime}$ and the frequency subsequently increases to $3.89 \mathrm{~Hz}$. Both RB models have iterations that exclude the joists. The frequency for the model with the $15^{\prime}$ height is $2.48 \mathrm{~Hz}$ and the model with the $13.25^{\prime}$ height is $3.89 \mathrm{~Hz}$.

The 3-D model is also the first to provide mode shapes in the EW direction since the direction is no longer restrained. According to the computational model, the mode shape in the EW direction for the unretrofit building is similar to that of a rigid diaphragm as the entire roof displaces in the EW direction as a unit. Once the braces are added, the edges of the diaphragm are held in place and the middle of the diaphragm displaces in the EW direction so that the diaphragm resembles a deep beam.

Though there are no EW frequencies and mode shapes from the test data to compare with the computational results, the computational results are instrumental in determining whether the natural frequencies of the building are in the range of testing. According to the computational model, the natural frequencies for the unretrofit building range from $1.62 \mathrm{~Hz}$ to $1.90 \mathrm{~Hz}$, which is in the range of the ambient vibration test (AVT). Similarly the retrofit building frequencies range from $2.48 \mathrm{~Hz}$ to $3.89 \mathrm{~Hz}$ which is in the range of the AVT and the forced vibration test (FVT). By using the mode shapes and frequencies obtained from the computational model it is possible to calculate, through modal analysis, what the recorded accelerations should have been due to the $30-1 \mathrm{~b}$ shaker. 
There was initial concern that the reason the EW modes were undetected was that the shaker did not produce large enough accelerations.

\subsection{Modal Analysis}

Through the modal analysis detailed below it is determined that had the natural frequency been in the range of testing, it would have been detected.

The building is simplified into a nine degree-of-freedom (DOF) structure by splitting the diaphragm into three sections, each with three DOFs. The nine DOF structure are then excited by a 30-lb harmonic force and the accelerations due to that excitation are calculated through modal analysis detailed in Chopra (2007).

$$
\mathrm{Mu}+\mathrm{Ku}=\mathrm{p},
$$

where $\quad \mathrm{M}$ is the mass matrix,

$\mathrm{K}$ is the stiffness matrix,

$\ddot{\mathrm{u}}$ is the acceleration,

$\mathrm{u}$ is the displacement, and

$\mathrm{p}$ is the forcing function.

$$
\mathrm{u}=\Phi \mathrm{q},
$$

where $\Phi$ is the mode shape and

$$
\mathrm{q} \text { is the modal coordinate. }
$$

Equation 9 is substituted into equation 8 and then orthonormalized by multiplying both sides of the equation by $\Phi^{\mathrm{T}}$, shown in equation 10 , which simplifies to equation 11 on the following page. 


$$
\begin{array}{rlr}
\Phi^{\mathrm{T}} \Phi \ddot{q}+\Phi^{\mathrm{T}} \Phi q & =\Phi^{\mathrm{T}} \mathrm{p} & \text { Eq. } 10 \\
\mathrm{I} \ddot{q}+\Omega^{2} \mathrm{q} & =\Phi^{\mathrm{T}} \mathrm{p}, & \text { Eq. } 11
\end{array}
$$

where I is the identity matrix and

$\Omega$ is a matrix with the natural frequencies on the diagonal.

Due to the orthonormalization, Equation 8 is able to be uncoupled and become equation 11. Equation 11 can separate into single-degree-of-freedom equations, (equation 12.)

$$
\ddot{q}+\omega_{\mathrm{n}}^{2} \mathrm{q}=\mathrm{P}_{0} \sin (\omega \mathrm{t})
$$

where $\quad \mathrm{P}_{0} \sin (\omega t)$ is the forcing function and

$\omega n$ is the natural frequency of the nth mode.

Once $\mathrm{q}$ is solved in equation 12 , the displacement $\mathrm{u}$ can be calculated using equation 9. The second derivative of $\mathrm{u}$, shown in equation 13, yields the acceleration of the diaphragm at the given point.

$$
\ddot{\mathrm{u}}=\mathrm{u} \omega^{2}
$$

These calculations predict an acceleration of approximately $900 \mu \mathrm{gs}$ for the first mode in the NS direction for both buildings. These are comparable to the accelerations found during testing which range from $760 \mu \mathrm{gs}$ to $1300 \mu \mathrm{gs}$.

The estimates for the accelerations in the EW direction for the URB are $550 \mu \mathrm{gs}$ and the accelerations in the EW direction for the RB are $6 \mu \mathrm{gs}$. 
The predicted accelerations drop from $550 \mu \mathrm{gs}$ at $1.86 \mathrm{~Hz}$ to $6 \mu \mathrm{gs}$ at $3.89 \mathrm{~Hz}$ due to the change in the EW mode shape during retrofit. According to the model, once the braces are added, the LFRS becomes sufficiently stiff enough that the diaphragm behaves like a flexible diaphragm between the brace lines. The mode shape, which originally was defined as a rigid body translation in the EW direction, behaves like a beam, bending between the brace lines. During the frequency sweeping, the accelerometers were placed near the brace line, which according to the new mode shape, barely moves. Assuming the computational model accurately predicts the mode shape of the building, this explains why the EW direction is not detected for the retrofit building. Because the sawtooth framing made the center of the roof inaccessible, the accelerometers were not placed in the optimum spot to excite the EW mode of the RB. However, the modal analysis clearly indicates that the first EW mode should have been identified for the unretrofit building if it was in the tested range.

According to the computational models, the EW mode should be approximately $1.86 \mathrm{~Hz}$ for the URB and $3.89 \mathrm{~Hz}$ for the RB. The ambient sweeps include these frequencies. Figure $\mathrm{Z}$ on the following page shows that there is no peak to indicate a mode in the EW direction. 


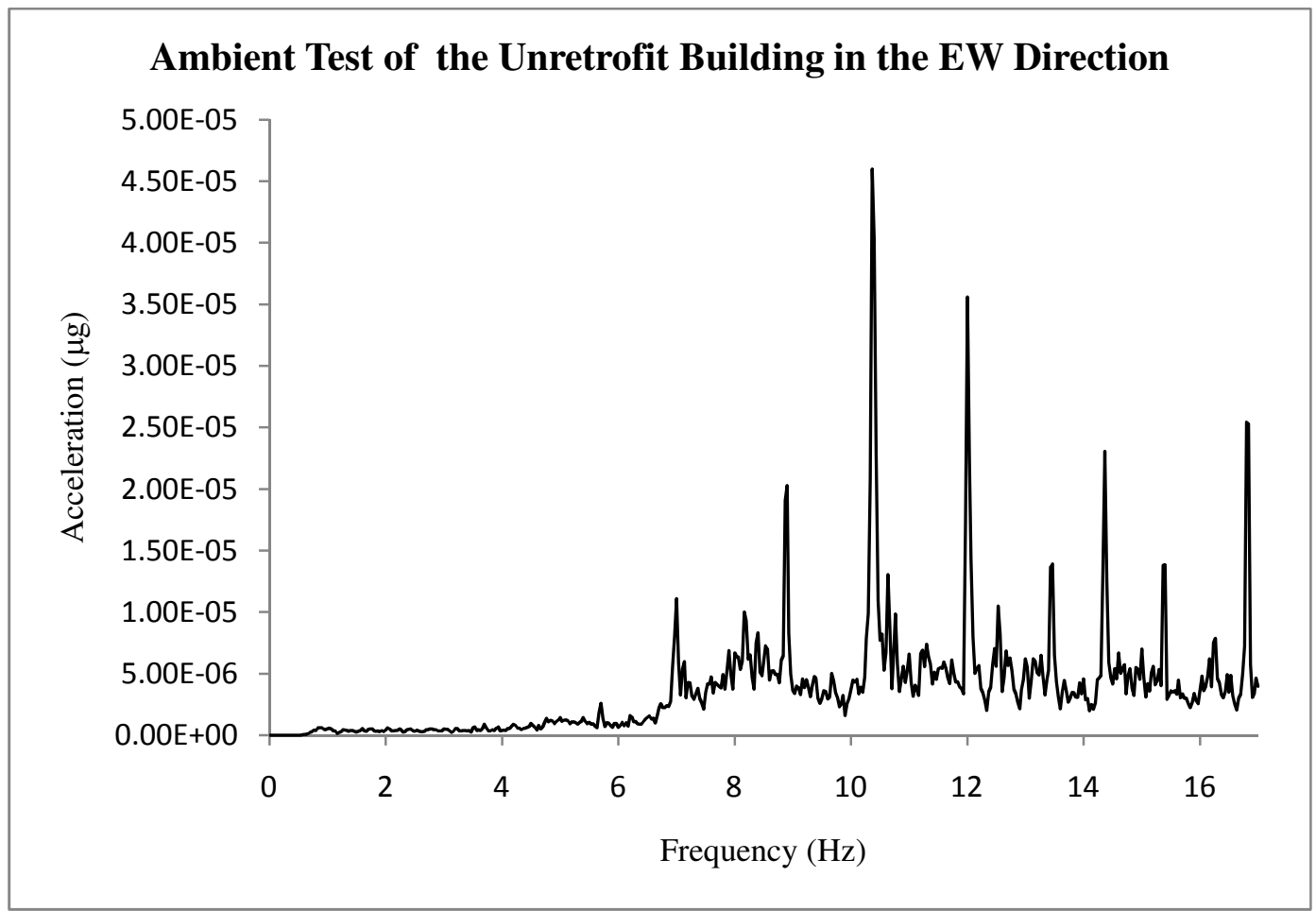

Figure Z: Ambient Vibration of the Unretrofit Building in the EW Direction Source: Jacobsen (2011)

As seen in Figure $\mathrm{Z}$, the range from $1 \mathrm{~Hz}$ to $6 \mathrm{~Hz}$ is virtually flat. The only peaks indicated in the EW ambient sweep are the peaks due to the mechanical units in the building that oscillate at the higher frequencies. If there is an EW mode at the frequency indicated by the computational models, it would have been recorded on the ambient vibration test. Despite the small level of excitation, the AVT proved to be a reliable indicator of what the natural frequency would be. In the NS direction, the AVT shows the first mode which the FVT also confirms. The ambient vibration for the NS direction is shown in Figure AA on the following page. 


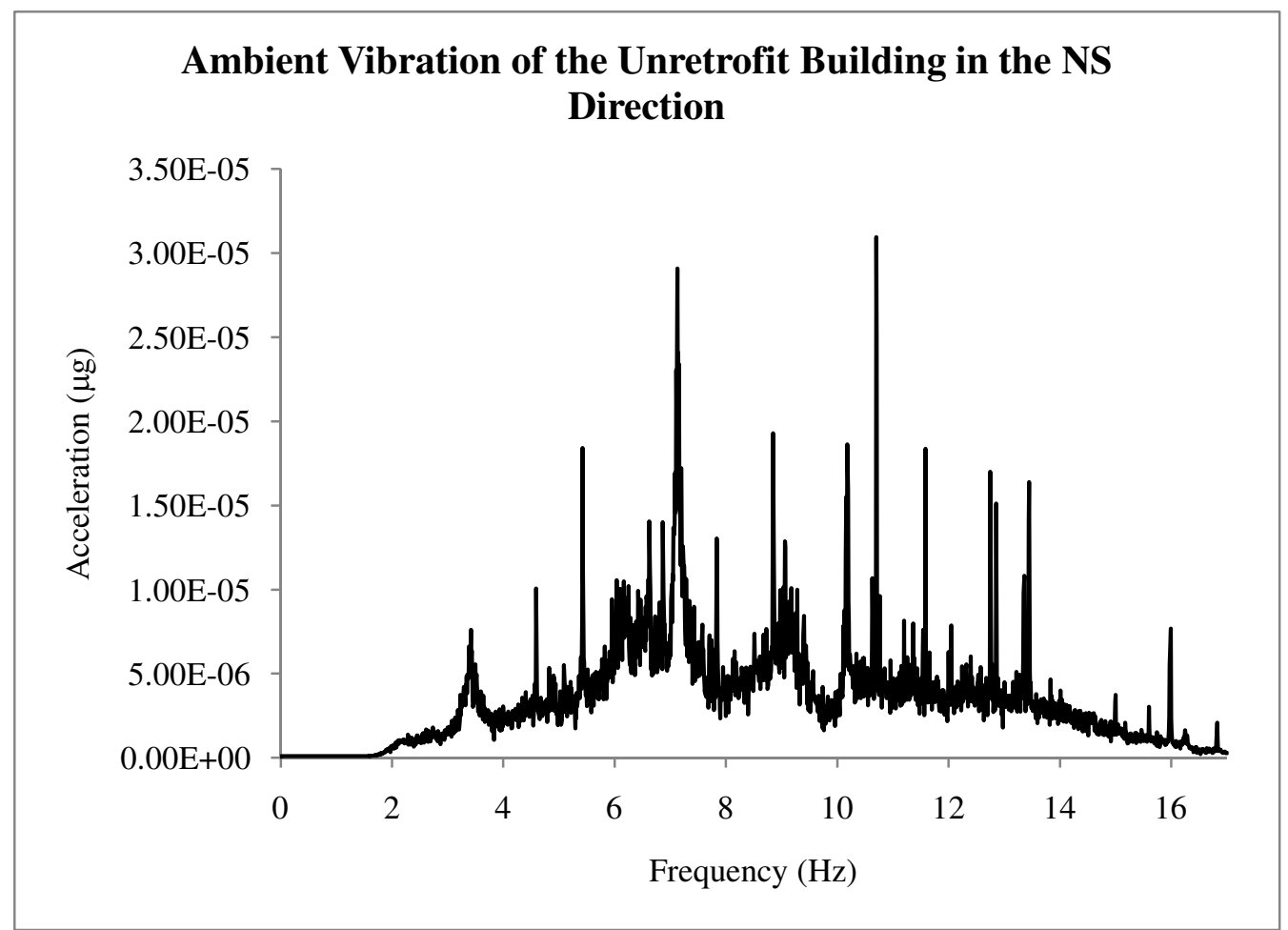

Figure AA: Ambient Vibration of the Unretrofit Building in the NS Direction Source: Jacobsen (2011)

In Figure AA, the peaks at $3.35 \mathrm{~Hz}$ and $6.18 \mathrm{~Hz}$ can be discerned in the ambient vibration, clearly indicating that the AVT is sensitive enough to detect a mode if it is within the range of testing. Similarly, the EW ambient vibration test for the retrofit building did not detect an EW mode as illustrated in Figure BB on the following page. 


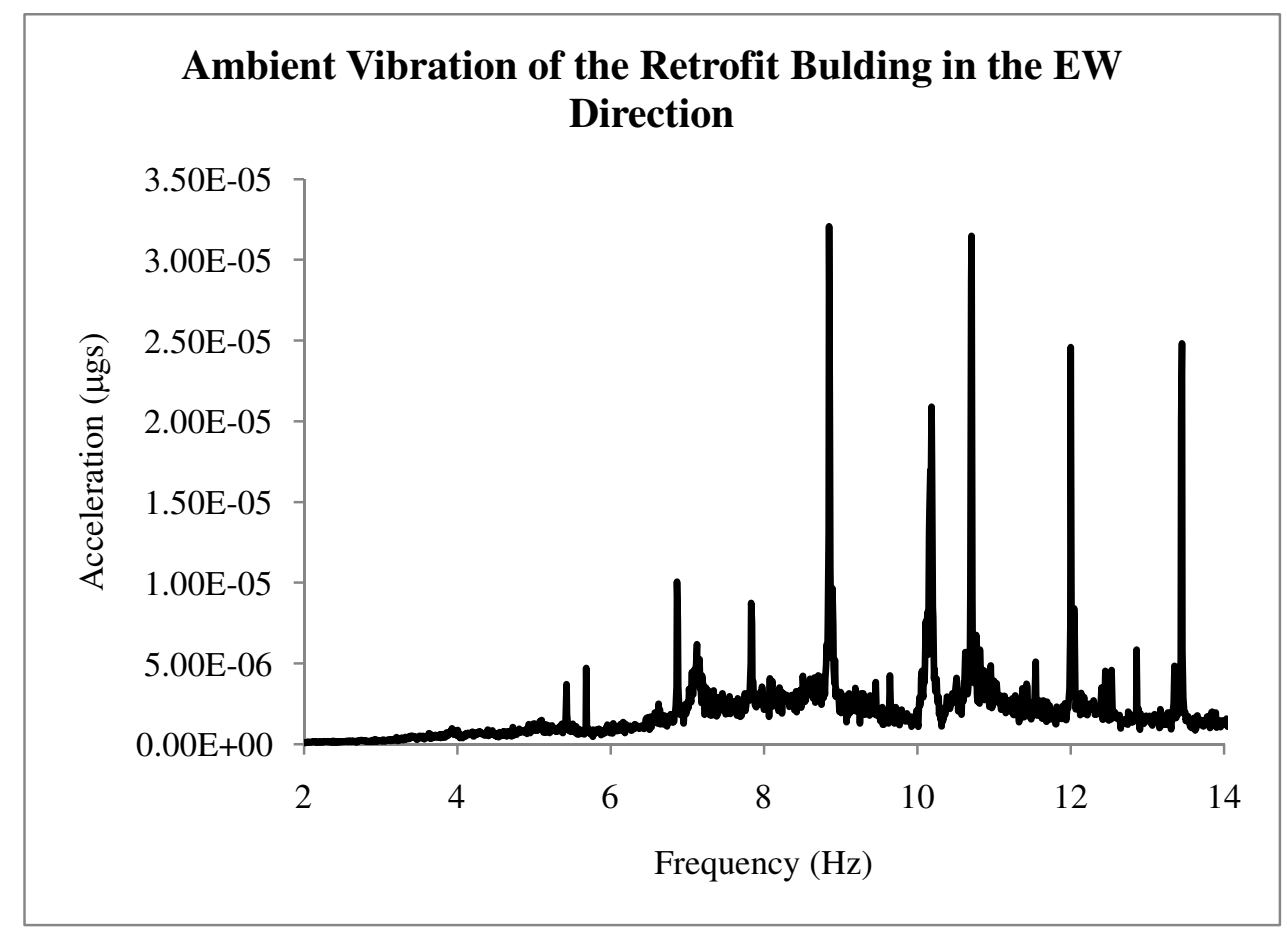

Figure BB: Ambient Vibration of the Retrofit Building in the EW Direction Source: Jacobsen (2011)

The predicted natural frequency for the RB is $3.89 \mathrm{~Hz}$. As is clear in Figure BB, there is no peak near $4 \mathrm{~Hz}$. The peaks indicated appear at the higher frequencies most likely due to the mechanical equipment located on the roof. That the AVT could detect the natural frequencies in the NS direction, shown in Figure CC on the following page, suggests that if the EW natural frequencies are within the range of the test, a peak should have appeared in Figure BB. 


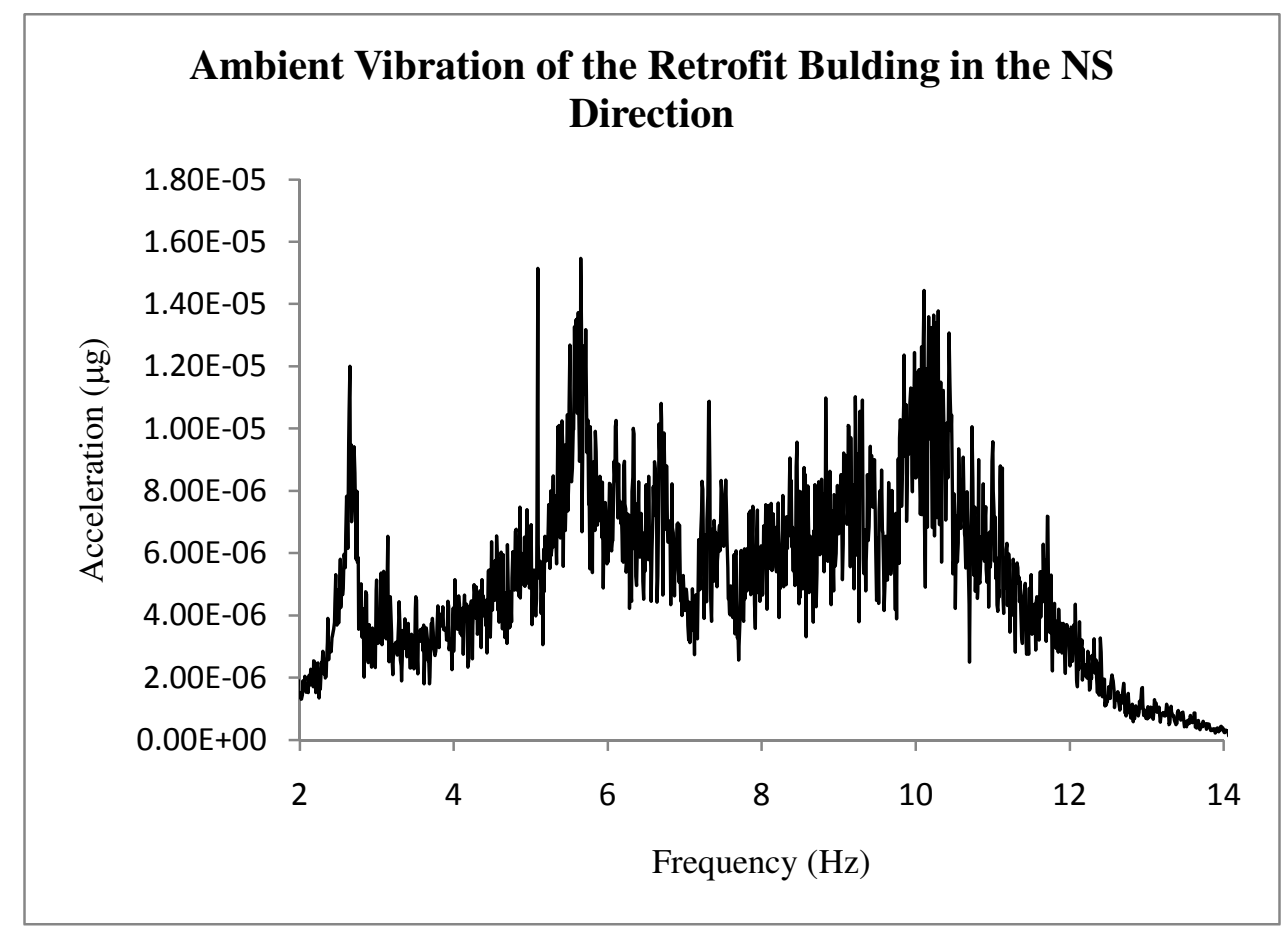

Figure CC: Ambient Vibration of the Retrofit Building in the NS Direction Source: Jacobsen (2011)

In Figure $\mathrm{CC}$ the peaks at the natural frequencies, $2.63 \mathrm{~Hz}$ and $5.58 \mathrm{~Hz}$, are

clearly discernible. These clear peaks are in contrast to Figure BB where no peaks appear at the predicted frequency range. The ambient vibration is capable of detecting the frequencies in the NS direction and it should have detected the frequencies in the EW direction. From the previous graphs it is apparent that had the natural frequencies fallen within the tested range, the AVT should have detected them. Failing that, the FVT would have detected them.

Previous testing using the same equipment, (McDaniel and Archer 2009) has always managed to locate the first mode of the building in each direction. As of yet, the testing of these buildings in the EW direction appears to be the only case where the first mode was not detected with this method of testing. That the NS modes were easily 
detected in both ambient and forced vibration testing and that testing on other buildings yielded results, suggests that the method isn't flawed but rather the predicted frequencies are inaccurate. Previous success with the testing method suggests that the natural frequencies of the EW modes are either higher than the tested range, above $18 \mathrm{~Hz}$, or lower than the tested range, below 1.5 Hz. Again, though the computational model may have been unsuccessful at predicting frequencies in the EW direction, the NS and EW modes are uncoupled so the computer model still successfully predicts the modes for NS direction.

\subsection{Summary}

The modeling process demonstrated that simplified models, such as hand calculations and the membrane models, did not accurately predict either building's modal behavior. The smallest percent difference between the hand calculations and the tested frequencies is $31.6 \%$; the smallest percent difference between the membrane models and the tested frequencies is $19 \%$. Though the simple models cannot accurately predict the natural frequencies they are instrumental in understanding the basic behavior of the building diaphragm.

The membrane model helped conclude that the gross section properties of the plywood should be used, rather than a thinner, more flexible membrane. The more complicated 2-D diaphragm models are better predictors of the building behavior but ultimately still underestimate the natural frequency by $31.2 \%$. The large difference 
between the diaphragm model frequencies and the tested frequencies prompted the creation of models that include the LFRS.

The final iteration of models includes the columns, walls, and braces in the EW direction and is able to accurately predict the building behavior. By including the LFRS the model predicts a natural frequency within $2 \%-3 \%$. Through the modeling process it was determined that all the main members: beams, girders, columns, shearwalls, and braces, must be included in the model in order to capture the building's behavior. The girders in the direction of testing stiffen the diaphragm by decreasing the span of the diaphragm and the girders in the transverse direction stiffen the diaphragm by effectively increasing its section modulus. The LFRS must be included as they stiffen the diaphragm by acting as springs throughout the diaphragm and restraining its movement. It is also apparent that the model must include the sawtooth framing in order to represent the building; the sawtooth does provide load transfer and therefore cannot be modeled as a hole in the diaphragm. However, small members, such as joists, can be excluded from the model without impacting the modal behavior.

The final model accurately predicts the NS natural frequencies, but it does not accurately predict EW frequencies. Though the predicted EW frequencies are in the range that was tested, no EW modes show up on the FVT graphs. Through modal analysis it was assessed that if the model is correct in the EW direction, the accelerations at the first two EW modes should have been detected. That the modes were not detected indicates that the model does not accurately capture the EW direction of the building. 
This does not impact the model's ability to predict the NS direction, however, since the two directions are uncoupled. 


\subsection{BUILDING RESPONSE}

The goal of creating the different models was to determine what level of detail was necessary to capture the behavior of the buildings. But in order to draw any conclusions, the criteria to evaluate the models needed to be established. One criterion was the natural frequencies of the models, and the other was the models' response to the two response spectra. One of the response spectra was the LA ground motion developed by the SAC Joint Venture (FEMA 355C) with a 475-year return period. The other response spectrum was the design spectrum published in the ASCE-7. Both spectra are shown below in Figure DD.

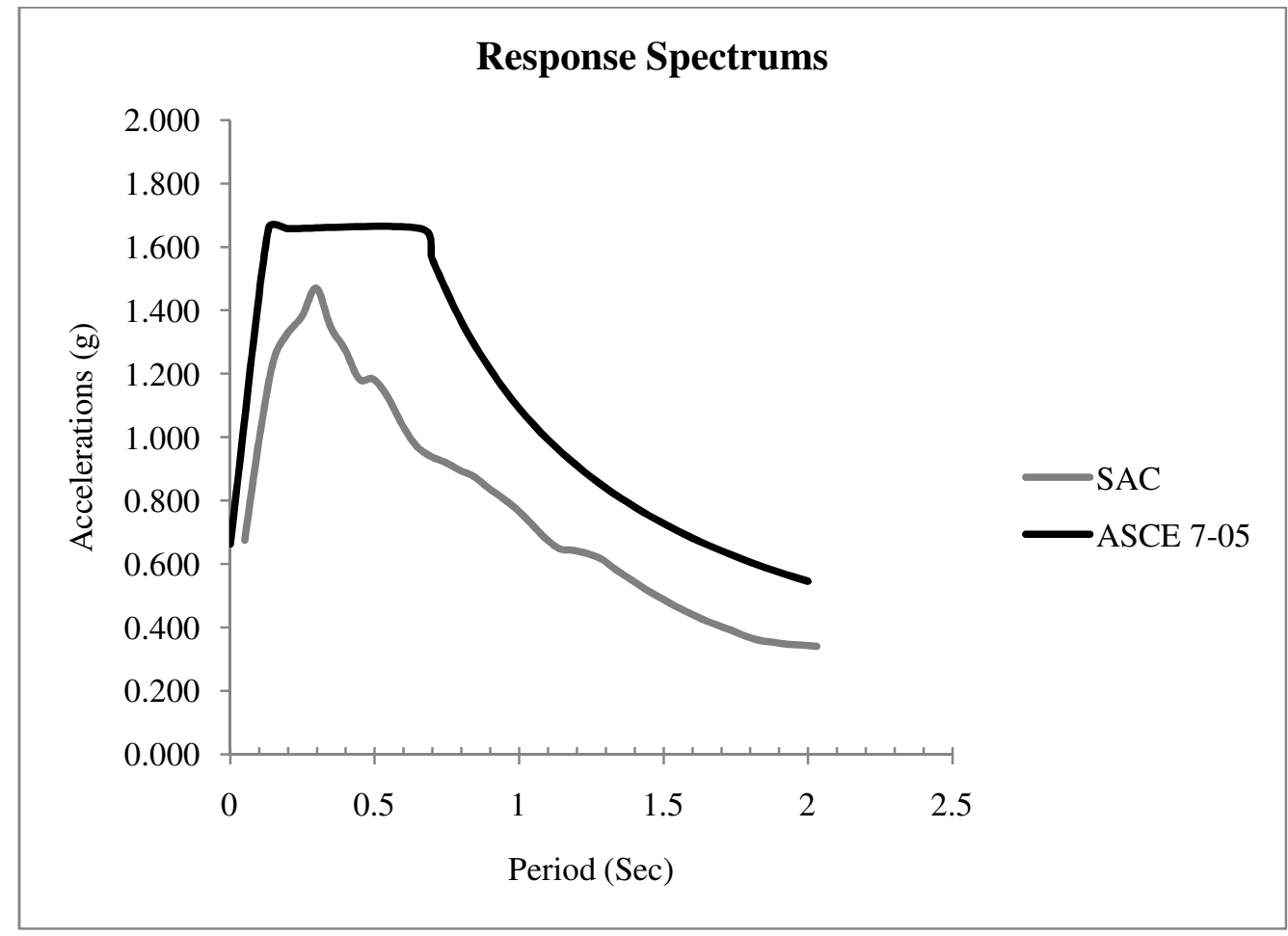

Figure DD: Response Spectra Used in Comparison of Models Source: Jacobsen (2011) 
It is beneficial to use spectra that are different from one another to ensure that the effects of changes to the model are universal regardless of the spectrum used. According to the ASCE-7 spectrum, a wide range of building frequencies have the same acceleration. The SAC spectrum is more sensitive to changes in building frequencies, making it a preferable spectrum for comparison. The two spectra have not been scaled to each other, so no comparison can be made between the two specifically, only between the different models.

Both response spectra are based on the experimental damping ratio obtained in testing, $3 \%$. Once all the criteria are recorded, the displacement at the center of the diaphragm, the total base shear, and the shear in the shearwalls, the models can be compared to each other and a conclusion can be drawn regarding what changes significantly affect the building responses.

Models that were thought to be a good approximation of the building, based on their ability to predict the natural frequency of the buildings, were chosen for this comparison. The baseline model is considered to be the model that best matches the experimental frequency. The best matched model is the 13.25 ' tall building with the sawtooth, all roof framing members, and in the case of the RB diagonal braces. These models are the baseline that the other models are compared against. The responses of the models are shown in Table 7 below. 
Table 7: Comparison of Responses for Different Unretrofit Building Models

Source: Jacobsen (2011)

\begin{tabular}{|c|c|c|c|c|c|}
\hline Model Description & & ASCE -7 & $\overline{\text { SAC }}$ & & \\
\hline Ba se Model: Complicated 3-D Model & & & & & \\
\hline$\# 1$ : Pre-R etrofit building with $13.25^{\prime}$ columns & Mid-Diaphragm $\Delta$ (in) & 1.75 & 2.02 & & \\
\hline and walls. All beams are modeled & Base Shear (kips) & 1235.47 & 1434.84 & & \\
\hline Saw tooth modeled as a slanted membrane. & Shear in Walls (kips) & 197.35 & 233.23 & & \\
\hline & & & & $\begin{array}{c}\% \text { Diff } \\
\text { ASCE-7 } \\
\end{array}$ & $\begin{array}{c}\text { \%Diff } \\
\text { SAC }\end{array}$ \\
\hline 3-D Model Variations & & & & & \\
\hline \#2: Pre-R etrofit building with 15 ' columns & Mid-Diaphragm $\Delta$ (in) & 2.07 & 2.55 & $18.3 \%$ & $26.2 \%$ \\
\hline and walls. All beams are modeled & Base Shear (kips) & 1169.61 & 1450.39 & $5.3 \%$ & $1.1 \%$ \\
\hline Saw tooth modeled as a slanted membrane. & Shear in Walls (kips) & 192.58 & 276.00 & $2.4 \%$ & $18.3 \%$ \\
\hline$\# 3$ : Pre-Retrofit buil ding with $13.25^{\prime}$ columns & Mid-Diaphragm $\Delta$ (in) & 1.76 & 2.03 & $0.6 \%$ & $0.5 \%$ \\
\hline and walls. Only major beams are modeled. & Base Shear (kips) & 1231.61 & 1434.61 & $0.3 \%$ & $0.0 \%$ \\
\hline Saw tooth modeled as a slanted m embrane. & Shear in Walls (kips) & 192.58 & 228.45 & $2.4 \%$ & $2.0 \%$ \\
\hline$\# 4$ : Pre-R etrof it buil ding with 15 ' columns & Mid-Diaphragm $\Delta$ (in) & 2.38 & 3.05 & $36.0 \%$ & $51.0 \%$ \\
\hline and walls. All beams are modeled. & Base Shear (kips) & 1090.85 & 1396.61 & $11.7 \%$ & $2.7 \%$ \\
\hline Saw tooth modeled as a hole in the diaphragm. & Shear in Walls (kips) & 137.97 & 176.80 & $30.1 \%$ & $24.2 \%$ \\
\hline 2-D Model Variations & & & & & \\
\hline$\# 5$ : Simply supported membrane with major & Mid-Diaphragm $\Delta$ (in) & 5.81 & 9.56 & $232.0 \%$ & $373.3 \%$ \\
\hline beam s. Sawtooth modeled as a slanted & Base Shear (kips) & 1802.36 & 2625.81 & $45.9 \%$ & $83.0 \%$ \\
\hline membrane. & Shear in Walls (kips) & N/A & $\mathrm{N} / \mathrm{A}$ & $\mathrm{N} / \mathrm{A}$ & $\mathrm{N} / \mathrm{A}$ \\
\hline
\end{tabular}

Table 7 shows several model variations: the base model, Model 1, which models all the beams, the sawtooth, and the LFRS; Model 2, which has a story height of 15' rather than 13.25'; Model 3, which models only the major beams; Model 4, which models the sawtooth as a hole rather than a slanted diaphragm; and Model 5, which does not model the LFRS. Though more models were generated, these three are thought to be most similar to those a practicing engineer might create. Modeling the building with a 15 ' story height, Model 2, produces a more significant change, with the diaphragm deflection increasing by $18 \%$ and $26.4 \%$. The model with only major beams included, Model 3, differs only slightly from the base model, with the highest percent difference being a $2 \%$ increase in shear in the walls. The model that produces the highest percent 
difference is Model 4 with no sawtooth framing, only a hole in the roof center. Model 4 has a diaphragm deflection increase of $36 \%$ and $51.2 \%$, and a base shear decrease of

\section{$11.7 \%$ and $2.7 \%$.}

One 2-D model is included, to prove that a 2-D model can not accurately predict any response criteria, not just natural frequencies. It is apparent in Table 7 that the 2-D model is the most disparate from the base model with an increase in diaphragm deflection of $231.9 \%$ and $373.8 \%$, and a base shear increase of $45.9 \%$ and $83 \%$.

The same comparison is performed on the retrofit building and the results of the response spectra on the models are shown below in Table 8.

\section{Table 8: Comparison of Retrofit Building Responses}

Source: Jacobsen (2011)

\begin{tabular}{|c|c|c|c|c|c|}
\hline \multicolumn{2}{|l|}{ Model Description } & ASCE -7 & SAC & & \\
\hline \multicolumn{4}{|l|}{ Ba se Model: Complicated 3-D Model } & & \\
\hline \multirow{4}{*}{$\begin{array}{l}\text { \#1: Post-R etrofit building with } 13.25^{\prime} \text { columns } \\
\text { and walls. All beams, braces, and tension rods } \\
\text { ar e modeled Sawtooth modeled as a slanted } \\
\text { m embrane. }\end{array}$} & \multirow{4}{*}{$\begin{array}{l}\text { Mid-Diaphragn } \Delta \text { (in) } \\
\text { Base Shear (kips) } \\
\text { Shear in Walls (kips) }\end{array}$} & \multirow{4}{*}{$\begin{array}{c}2.05 \\
1653.20 \\
239.33\end{array}$} & \multirow{4}{*}{$\begin{array}{c}2.52 \\
2066.23 \\
297.32\end{array}$} & & \\
\hline & & & & & \\
\hline & & & & & \\
\hline & & & & $\begin{array}{r}\% \text { Diff } \\
\text { ASCE-7 }\end{array}$ & $\begin{array}{c}\text { \%Diff } \\
\text { SAC }\end{array}$ \\
\hline \multicolumn{6}{|l|}{ 3-D Model Variations } \\
\hline \multirow{3}{*}{$\begin{array}{l}\text { \#2: Post-R etrofit building with } 15^{\prime} \text { columns } \\
\text { and walls. All beams, braces, and tension rods } \\
\text { ar e modeled Sawtooth modeled as a slanted } \\
\text { m embrane. }\end{array}$} & Mid-Diaphragm $\Delta$ (in) & 2.42 & 3.11 & $18.0 \%$ & $23.4 \%$ \\
\hline & Base Shear (kips) & 1425.89 & 1837.42 & $13.7 \%$ & $11.1 \%$ \\
\hline & Shear in Walls (kips) & 276.94 & 357.50 & $15.7 \%$ & $20.2 \%$ \\
\hline \multirow{3}{*}{$\begin{array}{l}\text { \#3: Post-R etrof it building with } 13.25^{\prime} \text { columns } \\
\text { and walls. Only maj or beams are modeled. Braces } \\
\text { and tension rods included Sawtooth model ed } \\
\text { as slanted membrane. }\end{array}$} & Mid-Diaphragm $\Delta$ (in) & 2.06 & 2.54 & $0.5 \%$ & $0.8 \%$ \\
\hline & Base Shear (kips) & 1487.75 & 1842.79 & $10.0 \%$ & $10.8 \%$ \\
\hline & Shear in Walls (kips) & 234.15 & 291.44 & $2.2 \%$ & $2.0 \%$ \\
\hline \multicolumn{6}{|l|}{ 2-D Model V ariations } \\
\hline \multirow{3}{*}{$\begin{array}{l}\text { \#- Simply supported membrane with major } \\
\text { beam s. Sawtooth modeled as a slanted } \\
\text { membrane. }\end{array}$} & Mid-Diaphragm $\Delta$ (in) & 5.81 & 9.56 & $183.4 \%$ & $279.4 \%$ \\
\hline & Base Shear (kips) & 1802.36 & 2625.81 & $9.0 \%$ & $27.1 \%$ \\
\hline & Shear in Walls (kips) & $\mathrm{N} / \mathrm{A}$ & $\mathrm{N} / \mathrm{A}$ & $\mathrm{N} / \mathrm{A}$ & $\mathrm{N} / \mathrm{A}$ \\
\hline
\end{tabular}

Table 8 is similar to Table 7 except no model was created of the RB with a hole in the diaphragm. All models include the retrofit with the sawtooth framing and slanted membrane. The two 3-D variations, Models 2 and 3, have some effect but remain close 
to the baseline model. The model with only major beams, Model 3, barely affects the deflection, by less than $1 \%$, but does change the base shear by almost $10 \%$. The model with the 15 ' story height, Model 2, has a greater effect with almost a $20 \%$ increase in deflection and approximately $12 \%$ decrease in base shear. The 2-D model, Model 4, is significantly different from the baseline model as expected since it has no vertical members. The base shear changes by $9 \%$ and $27.1 \%$, and the deflection of the diaphragm increases dramatically, $184.3 \%$ and $279 \%$.

Ultimately, the largest effect due to the changes is the diaphragm deflection, with the change in deflection ranging as high as $51 \%$ in the $3-\mathrm{D}$ models and $374 \%$ in the $2-\mathrm{D}$ diaphragm models. This dramatic change in diaphragm deflection indicates a wide range in responses depending on the assumptions that the engineer makes. However, if the diaphragm deflection is still below the allowable limit, the engineer may not be concerned regarding the overestimation of the deflection. Though the IBC (2006) limits the span-to-width ratio of the diaphragm, the actual deflection limit of the diaphragm is at the discretion of the engineer. Engineers must consider the effects of the diaphragm deflection on the walls beneath the diaphragm and decide whether the deflection is acceptable (Bryer et al. 2007). In the case of the 3-D models, the highest diaphragm deflection is $3.1 "$, resulting in a story drift of $1.7 \%$. This is an acceptable drift, so despite the changes had on the diaphragm deflection, the results could still be considered acceptable. Base shear and natural frequency change but to a lesser degree than the diaphragm deflection. 
The two response spectra analyses were done to the 2-D diaphragm model to illustrate the importance the LFRS. Table 7 on page 75 and Table 8 on page 76 how significantly the diaphragm deflection is affected by the interior moment frames.

Without the interior moment frames, the deflection increases by $231 \%$ and $373 \%$. Through this comparison it is apparent that the building cannot be accurately modeled with a diaphragm alone, even if the only response quantity desired is diaphragm deflection. The diaphragm and the vertical system cannot be evaluated separately since the stiffness of the diaphragm partially depends on the system below it.

The response spectra analyses confirm that in order to accurately predict the building response, the computational model must include the sawtooth framing, LFRS, and all major beams, columns, and walls. As seen in the frequency comparison, the exclusion of minor joists does little to the building response. However, contrary to the frequency comparison, the spectra analyses concluded that a $10 \%$ change in height changed the building response by a significant amount, anywhere from $10 \%$ to $24 \%$. The spectra analyses suggest that the height assumption can have a significant effect on the building responses and therefore a proper model should consider the correct effective height of the members. 


\subsection{CONCLUSIONS}

The first two natural frequencies for both the buildings were found through forced vibration testing (FVT). The first two natural frequencies for the unretrofit building (URB) are $3.35 \mathrm{~Hz}$ and $6.31 \mathrm{~Hz}$. The first two natural frequencies for the retrofit building (RB) are $2.66 \mathrm{~Hz}$ and $5.63 \mathrm{~Hz}$. Though the NS modes were easily detected in both buildings, the EW modes were undetected and modal analysis later confirmed that, despite computational model predictions, the EW natural frequencies were outside the range of testing, $2 \mathrm{~Hz}$ to $10 \mathrm{~Hz}$.

Without the EW natural frequencies, no mode shape testing could be done, so only the NS modes were mapped. The first NS mode was simple bending of the diaphragm with the maximum acceleration recorded in the center of the diaphragm. The second mode shape looked similar to the first mode, indicating a large amount of modal pollution from the first mode. However, even after the first mode was swept out of the second mode, Mode 2 is not pure double bending and shows the two sides of the diaphragm moving opposite to each other. One possible explanation for the shifted double bending is varying stiffness or mass along the length of the diaphragm. The stiffness of the diaphragm could vary over the length of the diaphragm due to the sawtooth or inconsistencies in the construction. The sawtooth framing is significantly less stiff than the flat diaphragm framing and that change in stiffness could affect Mode 2.; Lumped mass at one end could cause the shift in Mode 2 and there were mechanical units for both the RB and URB located at the west end of the building. 
While the shifted mode shape could be explained by varying stiffness or mass, an explanation for the two sides of the diaphragm moving opposite to each other could be the plywood diaphragm flexing on top of the steel frame. The plywood is nailed to wood joists that sit on top of the steel wide flanges, so there is a chance that the plywood moves on top of the frame without engaging the wide flanges. Though this flexibility in the connections is contrary to the assumption made during modeling, that the plywood membrane acts as unit, the possibility could not be ruled out during testing.

Another likely explanation for the distortion of Mode 2 is modal pollution from higher modes interfering with Mode 2. A third peak on the FVT graph close to the second natural frequency suggests that Mode 3 is close to Mode 2 and participation from Mode 3 may be polluting the results for Mode 2 .

In comparing the results of computational models to the test results of two stiffwall/flexible-diaphragm buildings it became clear that while simple hand calculations did a fair job of approximating the natural frequency of the building, a more complex computational model is required to accurately capture the building's modal behavior. The initial computational models garnered improved results from the hand calculations, with more accurate natural frequencies and mode shape predictions in the NS direction. Among the multiple membrane and 2-D diaphragm models the lowest percent difference from the tested natural frequencies was $19 \%$. Though the early models can predict mode shapes in the NS direction, a drawback of models that excludes the vertical systems is their inability to predict modal behavior in the EW direction. Due to the inaccuracy of 
the frequency predictions and the limit of modal behavior in the EW direction, a more complex model is necessary.

The models that are able to accurately predict the modal behavior in the NS direction include the sawtooth framing, moment frames, shearwalls, and brace frames in the case of the retrofit building. The sawtooth framing must be modeled to represent the load path through the sawtooth. If the sawtooth framing is not well connected to the diaphragm it may be more accurate to model a hole in the diaphragm, however in the case of these buildings, there is a clear load path through the sawtooth and it is inaccurate to exclude the sawtooth from the model. The girders are necessary as they help to provide stiffness to the diaphragm. The diaphragm spans between the girders and so by including the girders parallel to the direction of loading, the span of the diaphragm is reduced and the diaphragm is stiffened. The girders perpendicular to the direction of loading act as part of the diaphragm and increase its section modulus, therefore also increasing its stiffness. Finally, the LFRS must also be included in the model as the LFRS acts as springs between the diaphragm and the ground, providing a semi-rigid connection. The deflection of the diaphragm cannot be accurately predicted without consideration of the LFRS.

The model including the sawtooth framing, girders, and LFRS is able to predict natural frequencies within $3 \%$ of the experimental results, the closest match of any of the computational models, confirming the importance of including all of these components. The model also predicts the first mode shape in the NS direction to be simple bending of 
the diaphragm, similar to what the testing revealed. Though the model is successful at predicting the NS direction, the EW predictions do not match the test results. Neither the AVT nor the FVT tests detected any natural frequencies in the range the computational model predicts, suggesting that the computational model does not accurately capture the EW behavior of the buildings.

Though the EW natural frequencies were out of range of the testing, either lower than $1.5 \mathrm{~Hz}(\mathrm{~T}=0.67 \mathrm{sec})$ or higher than $10 \mathrm{~Hz}(\mathrm{~T}=0.1 \mathrm{sec})$, effects of the retrofit can be discerned from the other results. The retrofit scheme consists of braces in the EW direction so the NS direction should not be affected. Through testing and computational modeling, this prediction is confirmed as the natural frequencies of the retrofit building shift down due to the increase in mass of the retrofit building, rather than up due to the stiffening of the building. The mode shape in the NS direction is also unaffected by the retrofit in both the testing and the computational modeling.

The experimental method works well for predicting the modal behavior of the building. The buildings tested in this thesis are larger than any others tested with this method, and all previously tested buildings consisted of rigid diaphragms rather than flexible diaphragm. It was originally thought that the $30-1 \mathrm{~b}$ shaker would be unable to excite the entire building and that only the diaphragm membrane would be excited. Clear results were acquired for the NS direction that were confirmed with the computational model, verifying that FVT with the small shaker is able to predict the natural frequencies of the building. The inability to predict the natural frequency in the EW direction is not a 
limitation of the testing equipment, rather it is thought that the EW natural frequencies lie outside the range of interest, $2 \mathrm{~Hz}$ to $10 \mathrm{~Hz}$, or in some cases that the equipment was not ideally placed to excite the building. Overall, the mode shape testing was successful, particularly at predicting Mode 1, but participation from higher modes made it difficult to discern Mode 2. This amount of modal pollution is likely due to the flexible diaphragm as previous testing on rigid diaphragms has been able to determine the first two and even three modes of the buildings.

For future testing on flexible diaphragms it is recommended that modal analysis of the building be completed before testing begins. Modal analysis can help predict whether accelerations can be detected and also help predict the optimum locations to excite the building. Better understanding of the predicted modes shapes could ultimately lead to more conclusive testing, whether to prove or disprove the predicted shapes. 
7.0 Works Referenced List 84

\subsection{WORKS REFERENCED LIST}

(APA 1998) Plywood Design Specification. American Plywood Association. 1998. Web. 1 September 1998. <http://www.apawood.org >

(ASCE 2005) ASCE 7-05: Minimum Design Loads for Building and Other Structures. American Society of Civil Engineers. 2005. Print.

(Breyer et al. 2007) Breyer, Donald E., et al. Design of Wood Structures: ASD/LRFD. New York: McGraw Hill Companies, Inc. 2007. Print.

(Camelo 2003) Camelo, Vanessa. Dynamic Characteristics of Wood Frame Buildings. California Institute of Technology. Pasadena: 2003. Print.

(Chopra 2007) Chopra, Anil K. Dynamics of Structures: Theory and Applications to Earthquake Engineering. Upper Saddle River: Pearson Prentice Hall, 2007. Print.

(FEMA 1998) FEMA 310: Handbook for the Seismic Evaluation of Buildings--A Prestandard. Federal Emergency Management Agency. 1998. Print.

(Freeman, Searer, and Gilmartin 2002) Freeman, Sigmund A., Gary R. Searer, and Una M. Gilmartin, "Proposed Seismic Design Provisions for Rigid Shear Wall/Flexible Diaphragm Structures." Proceedings for Seventh U.S. National Conference on Earthquake Engineering. 2002. Print.

(IBC 2006) International Building Code 2006. International Code Council. Country Club Hills: 2006. Print.

(Ivanovic 2000) Ivanovic, S.S., et al. "Ambient Vibration Tests of a Seven-Story Reinforced Concrete Building in Van Nuys, California, Damaged by 1994 Northridge Earthquake" Soil Dynamics and Earthquake Engineering 19 (2000): 391411. Print.

(Ivanovic et al 2000) Ivanovic, S.S., M. D. Trifunac, and M.I Todorovska. "Ambient Vibration of Structures - A Review." ISET Journal of Earthquake Technology, Vol 37. December 2000: 165-197. Print.

(Lawson 2007) Lawson, John W. "Thinking Outside the Box: New Approaches to Very Large Flexible Diaphragms." Proceedings from SEAOC 2007 Convention. Squaw Creek, California: SEAOC, 2007. Print. 
(Luco, Trifunac and Wong 1988) Lucco, J.E. , M.D. Trifunac, and H.L. Wong. "Isolation of Soil-Structure Interaction Effects by Full-Scaled Forced Vibration Tests" Earthquake Engineering and Structural Dynamics 16 (1988): 1-21. Print.

(McDaniel and Archer 2010) McDaniel, C.C., and G. Archer. "Full-Scale, Real-Time Building Dynamics Laboratory." Proceedings for Toronto Conference. 2010. Print.

(Paquette and Bruneau 2005) Paquette, Jocelyn, and Michel Bruneau. "Psuedo-Dynamic Testing of Unreinforced Masonry Building With Flexible Diaphragm and Comparison With Existing Procedures." Construction and Building Materials 20 (2006): 220-228. Web. 17 October $2005<$ http://www.sciencedirect.com>.

(Rao 2004) Rao, Singiresu S.. Mechanics of Vibrations. $4^{\text {th }}$ Edition. Upper Saddle River: Pearson Education Inc. 2004. Print.

(Rogers and Tremblay 2005) Rogers, Colin A., and Robert Tremblay. "Impact of Diaphragm Behavior on the Seismic Design of Low-Rise Steel Buildings" Proceedings for Nashville Steel Conference. 2005. Print.

(SEAOC Seismology Committee 2008). "Tilt-up Buildings," September, 2008, The SEAOC Blue Book: Seismic design recommendations, Structural Engineers Association of California, Sacramento, CA.

(SEAONC 2001) Guidelines for Seismic Evaluation and Rehabilitation of Tilt-Up Buildings and Other Rigid Wall/Flexible Diaphragm Structures. Structural Engineers Association of Northern California. San Francisco, CA. 2001. Print.

(Trifunac 1972) Trifunac, Mihailo D.. "Comparisons Between Ambient and Forced Vibration Experiments" Earthquake Engineering and Structural Dynamics 1 (1972): 133-150. Print. 
8.0 Works Consulted List 86

\subsection{WORKS CONSULTED LIST}

(Bott 2005) Bott, James Wescott. Horizontal Stiffness of Wood Diaphragms. Virginia Polytechnic and State University. Blacksburg: 2005. Print.

(CSI 2008) ETABS 9.5.0 User's Guide, Computers \& Structures Inc., Berkeley, CA. Print.

(Doebling et al. 1998 ) Doebling, S.W., Charles R. Farrar, and Michael B. Prime. "A Summary Review of Vibration-Based Damage Identification Methods." Shock and Vibration Digest, Vol. 30, 91-105. Print.

(Hans et al. 2005) Hans, S., C. Boutin, E. Ibraim, and P. Roussillon. "In Situ Experiments and Seismic Analysis of Existing Buildings Part I: Experimental Investigations." Earthquake Engineering and Structural Dynamics, Vol. 34. 1513-1529. Web. 1 June $2005<\mathrm{http}: / / \mathrm{www}$.interscience.wiley.com>.

(Nakashima and Chusilp 2003) Nakashima, Masayoshi and Praween Chusilp. "A Partial View of Japanese Post-Kobe Seismic Design and Construction Practices" Earthquake Engineering and Engineering Seismology 4 (2003): 3-13. Print.

(Skaggs and Martin 2004) Skaggs, Thomas D, and Zeno A. Martin "Estimating Wood Structural Panel Diaphragm and Shear Wall Deflection." Practice Periodical on Structural Design and Construction. ASCE. 2004. Print.

(Wallace and Skolnik 2007) "Forced Vibration Testing: An Earthquake Damaged Reinforced Concrete Building." STRUCTURE Magazine. July 2007: 26-30. Print.

(Xie 2005) Xie, Qiang "State of the Art of Buckling-Restrained Braces in Asia." Journal of Constructional Steel Research 61 (2005): 727-748. Print. 